\title{
Perceived air quality and cognitive performance decrease at moderately raised indoor temperatures even when clothed for comfort
}

\author{
Lan, Li; Xia, Lulu; Hejjo, Rihab; Wyon, David P.; Wargocki, Pawel
}

Published in:

Indoor Air

Link to article, DOI:

10.1111/ina.12685

Publication date:

2020

Document Version

Peer reviewed version

Link back to DTU Orbit

Citation (APA):

Lan, L., Xia, L., Hejjo, R., Wyon, D. P., \& Wargocki, P. (2020). Perceived air quality and cognitive performance decrease at moderately raised indoor temperatures even when clothed for comfort. Indoor Air, 30(5), 841-859. https://doi.org/10.1111/ina.12685

\section{General rights}

Copyright and moral rights for the publications made accessible in the public portal are retained by the authors and/or other copyright owners and it is a condition of accessing publications that users recognise and abide by the legal requirements associated with these rights.

- Users may download and print one copy of any publication from the public portal for the purpose of private study or research.

- You may not further distribute the material or use it for any profit-making activity or commercial gain

- You may freely distribute the URL identifying the publication in the public portal 
DR. LI LAN (Orcid ID : 0000-0003-3431-9266)

DR. DAVID P. WYON (Orcid ID : 0000-0002-3329-3343)

DR. PAWEL WARGOCKI (Orcid ID : 0000-0003-3865-3560)

Article type : Original Article

\section{Perceived Air Quality and Cognitive Performance Decrease at Moderately Raised Indoor Temperatures Even When Clothed for Comfort}

Li Lan ${ }^{1,2}$, Lulu Xia ${ }^{1,2}$, Rihab Hejjo1, David P Wyon², and Pawel Wargocki² ${ }^{*}$

${ }^{1}$ Department of Architecture, School of Design, Shanghai Jiao Tong University, Shanghai 200240, China.

2 International Centre for Indoor Environment and Energy, DTU Civil Engineering, Technical University of Denmark, Kongens Lyngby, Denmark

Corresponding author: Pawel Wargocki, paw@byg.dtu.dk

\section{Abstract}

This study investigated whether adjusting clothing to remain in neutral thermal comfort at moderately elevated temperature is capable of avoiding negative effects on perceived acute subclinical health symptoms, comfort and cognitive performance. Two temperatures were examined: $23^{\circ} \mathrm{C}$ and $27^{\circ} \mathrm{C}$. Twelve subjects were able to remain thermally comfortable at both temperatures by adjusting their clothing. They rated the physical environment, their comfort, the intensity of acute subclinical health symptoms and their mental load and they performed a number of cognitive tasks. Their physiological reactions were monitored. Their performance of several tasks was significantly worse at $27^{\circ} \mathrm{C}$ and they This article has been accepted for publication and undergone full peer review but has not been through the copyediting, typesetting, pagination and proofreading process, which may lead to differences between this version and the Version of Record. Please cite this article as doi: $\underline{10.1111 / \text { INA.12685 }}$

This article is protected by copyright. All rights reserved 
reported increased mental load at this temperature. Skin temperature and humidity and respiration rate were higher while blood oxygen saturation $(\mathrm{SpO} 2)$ and pNN50 were lower at this temperature, the latter indicating increased stress. It is inferred that the observed physiological responses were mainly responsible for the negative effects on performance, as the subjects did not indicate any increased intensity of acute subclinical health symptoms although perceived air quality was worse at the higher temperature. The present results suggest that moderately elevated temperatures should be avoided even if thermal comfort can be achieved, as it may lead to reduced performance.

Keywords: air temperature; work performance; physiological responses; acute subclinical health symptoms; thermal comfort; elevated temperature

\section{Practical implications}

It is frequently assumed that there will be no effects on cognitive performance if no thermal discomfort is experienced. The present results suggest that this is not true and that moderately elevated temperatures should be avoided even if thermal comfort can be achieved. The present study shows that temperature and thermal discomfort should be treated separately and not interchangeably and that both must be optimized to provide conditions supporting comfort, health, and cognitive performance. This means additionally that setting thermostats on the basis of thermal comfort alone might lead to economic loss due to reduced performance. These conclusions are subject to experimental confirmation in other climatic regions.

\section{Introduction}

The thermal environment is one of the most important indoor environmental factors that affect human health and performance and is readily perceived by building occupants. Elevated temperatures that caused thermal discomfort have been shown to produce measurable changes in physiological responses including higher sympathetic nervous system activity as indicated by the increased ratio of low-frequency power to high-frequency power (LF/HF) of measured heart rate variability (HRV) [1-3]. It is also well documented that increased temperatures and thermal discomfort can result in acute

This article is protected by copyright. All rights reserved 
subclinical health symptoms such as headache, fatigue, and difficulty in concentrating $[1,4,5]$ and that they can negatively affect the cognitive performance of both adults performing office-like type of work and children performing schoolwork [3,6-12]. Heat stress has additionally been shown to cause a significant decline in the performance of attention-demanding tasks [13].

The predicted relationship between thermal environment and group average performance follows a bell-shaped curve centred around the conditions that are optimal for performance defined either by temperature [6] or by thermal sensation [7]. They both tend to suggest that a slightly cool environment and avoidance of moderately elevated temperatures will create conditions that are optimal for cognitive performance and this applies even to subjects who are acclimatized to higher temperatures by living in tropical climates [14]. The major question that has not been sufficiently resolved is whether the effects on performance at elevated temperatures are caused by temperature, by perceived thermal discomfort or by both $[15,16]$. If the effects are caused by thermal discomfort itself, it would be reasonable to assume that achieving a state of neutral thermal comfort would be sufficient to avoid the adverse effects of raised temperature on acute subclinical health symptoms and cognitive performance.

This assumption has been implicitly adopted by many standards $[17,18]$. Provided that building occupants are able to maintain neutral thermal comfort at higher temperatures by means of adaptive behaviours, e.g. by adapting clothing, opening windows, reduced activity or simply by psychological adaptation, many standards now state that higher temperatures in buildings would be justified, reducing the need for mechanical cooling. If correct, the application of this approach would make it possible to conserve substantial amounts of energy. It was recently postulated [19] that according to the maximal adaptability model [20], increased temperatures would not have negative effects on cognitive performance as cognitive adjustments to task demands are quickly enacted, creating an "extended U-curve". This claim was based on a review of published studies that examined the effects of the thermal environment on cognitive performance, but the review was not restricted to studies of effects on performance at thermal conditions in which subjects were in a state of neutral thermal comfort. What is more, the claim applies to the performance of individuals rather than to the average

This article is protected by copyright. All rights reserved 
performance of groups of individuals, who inevitably have different temperatures for their own optimal performance. Any change from the group optimal temperature will result in a decrease in group average performance as more and more individuals start to exceed the thermal range within which they can individually maintain their performance, and this is what has been observed.

Wyon et al. (1975) examined whether the performance of subjects was different when they were able to remain thermally neutral at $18^{\circ} \mathrm{C}$ and $23^{\circ} \mathrm{C}$ by wearing clothing with very different levels of thermal insulation. No differences in performance were observed [21]. Zhang et al. (2017a) examined whether raising the room temperature from $22^{\circ} \mathrm{C}$ to $25^{\circ} \mathrm{C}$ would cause any negative effects on performance and mental load [22]. The subjects in their study reported feeling slightly warmer at the higher temperature but no significant changes in performance were seen, although this could have been because learning was able to compensate for any negative effect of warmth, as the temperature of $25^{\circ} \mathrm{C}$ was always experienced as the second condition. Fang et al. (2002) exposed subjects to three different combinations of temperature and relative humidity: $20^{\circ} \mathrm{C}-40 \%, 23^{\circ} \mathrm{C}-50 \%$ and $26^{\circ} \mathrm{C}-60 \%$ [5]. Under each condition, the subjects remained thermally neutral by adjusting their clothing. Although no adverse effects on cognitive performance could be shown, subjects reported reduced perceived air quality and increased intensity of acute subclinical health symptoms (headache and fatigue), especially in the $26^{\circ} \mathrm{C}-60 \%$ condition. Häggblom et al. (2011) assessed whether temperatures of $21^{\circ} \mathrm{C}, 25^{\circ} \mathrm{C}$, and $29^{\circ} \mathrm{C}$ could affect cognitive performance. Increased temperature reduced performance even at $25^{\circ} \mathrm{C}$ but subjects reported progressively feeling warmer with increasing temperatures [23]. Wyon et al. (1996) examined driver vigilance when driving a car at $21^{\circ} \mathrm{C}$ or $27^{\circ} \mathrm{C}$ [24]. At the higher temperature which was stated to have caused only very moderate heat stress and no spontaneous complaints of thermal discomfort, the drivers missed a significantly higher proportion of signals presented to them at random and their response time to the signals they did perceive was significantly longer. Lan et al. (2011a) examined two temperatures, $22^{\circ} \mathrm{C}$ and $30^{\circ} \mathrm{C}$, at which subjects felt respectively thermally neutral and thermally warm, and showed negative effects on cognitive performance, increased intensity of symptoms, and reduced perceived air quality at the higher temperature [2]. The above results suggest that increased temperatures above the range defined in the present standards as the

This article is protected by copyright. All rights reserved 
thermal comfort zone, $18^{\circ} \mathrm{C}$ to $26^{\circ} \mathrm{C}$ [18], may produce negative effects on performance, on acute subclinical health symptoms and on perceived air quality but none of the experiments examined the effects of these higher temperatures while maintaining subjects in a state of neutral thermal comfort.

The objective of the present research was to examine this particular question. We investigated whether moderately elevated temperatures affect perceived air quality, acute subclinical health symptoms, and cognitive performance even when subjects remain in a state of neutral thermal comfort. The work is an extension of the study published by the authors in 2011 [2] in which it was not possible to examine this question $[15,16]$, so the present work used the same experimental protocol as far as possible.

\section{Methods}

\subsection{Approach}

The experiments were carried out in Denmark in October 2018. Subjects were recruited to be exposed in an office space to two temperatures, at $23^{\circ} \mathrm{C}$ and $27^{\circ} \mathrm{C}$, termed $\mathrm{T} 23$ and $\mathrm{T} 27$, respectively. These two temperatures were selected during pilot experiments, one of them well within the thermal comfort zone as defined by current standards (e.g., [18]) and the other slightly above it. The subjects were to remain in a state of neutral thermal comfort under both conditions. Other conditions such as the ventilation rate, noise level and illuminance remained unchanged, including the absolute humidity; relative humidity thus decreased with increased temperature. The subjects performed tasks typical of office work and neurobehavioral tests designed to assess different cognitive skills. Physiological responses and biomarkers were monitored during the exposures. The subjects rated perceived air quality, thermal comfort, the intensity of acute subclinical health symptoms sometimes termed Sick Building Syndrome (SBS) symptoms, fatigue, sleepiness, their workload and their performance, on visual-analogue scales.

\subsection{Facilities}

This article is protected by copyright. All rights reserved 
The study was carried out in a low polluting office (see the ratings of odour intensity and acceptability in the Results section) adapted for experimental purposes that was similar to the one used by Lan et al. (2011a) [2]. Six workstations were set up in the office. Adjacent workstations were separated by partitions (extending to about 1 meter above the floor) to ensure that subjects would not disturb each other. Each workstation consisted of a table, a chair, a desk lamp, a table fan, and a laptop; table fans were provided only in case thermal comfort could not be maintained by adjusting clothing, and none of the subjects did in fact use them during the experiments. The temperatures in the office were achieved by controlling the temperature of the air supplied to the office by the central ventilation system and by electric oil heaters connected to a calibrated temperature sensor located centrally in the occupied floor space; the heaters were controlled with a Proportional Integral Differential (PID) controller.

\subsection{Subjects}

Six female and six male subjects participated in the experiment. They were recruited by placing posters and announcements around the campus of the Technical University of Denmark. They were between 18 and 30 years old, and they were all students at the Technical University of Denmark. They were all Caucasian but of different nationalities; all tests were presented to them in English, which they all understood. The subjects did not have chronic diseases, asthma, allergy, hay fever or colour blindness, according to their responses to a questionnaire distributed to them during recruitment. None of them was examined medically.

During the week preceding the experiment, the subjects attended two practice and instruction sessions, each on a different day. One session took place at T23 and one at T27. One purpose was to rehearse the experimental procedure and to perform cognitive tasks to reduce the expected gradual improvement of performance with the number of times the task is performed, due to learning. Another purpose was to encourage the subjects to maintain a state of neutral thermal comfort at each temperature by adjusting their clothing. Initially, it was planned to use the temperatures $22^{\circ} \mathrm{C}$ and $30^{\circ} \mathrm{C}$, the conditions examined in the study of Lan et al. (2011a) [2] but the former temperature could not be

This article is protected by copyright. All rights reserved 
obtained because the ventilation system was not capable of removing enough of the heat generated in the office during the experiments. There was no cooling in the office and outdoor temperatures were higher than normal during the period when the experiments were carried out, which was in October 2018 (with an average temperature of $11^{\circ} \mathrm{C}$; range $1-18^{\circ} \mathrm{C}$ ), while the study of Lan et al. (2011a) [2] was carried out in January 2009 (with an average temperature of $-0.3^{\circ} \mathrm{C}$; range $-6.4^{\circ} \mathrm{C}$ to $+5^{\circ} \mathrm{C}$ ). The lower temperature condition was therefore increased to $23^{\circ} \mathrm{C}$, which lies well within the zone of thermal comfort zone prescribed by current standards (e.g., [18]). At $30^{\circ} \mathrm{C}$, the subjects could not achieve thermal neutrality when wearing socially acceptable office-like clothing (shorts or skirts, and t-shirts). Even the use of small fans operated at very low speed so as not to create too high air velocity in the facial region was not sufficient to allow the subjects to achieve neutral thermal comfort. After a few trials, it was decided to use the temperature of $27^{\circ} \mathrm{C}$, at which clothing could be socially acceptable and at which there was no need to use small fans. This temperature is outside the thermal comfort zone defined by current standards (e.g., [18]) for offices with mechanical cooling. In Denmark, the temperature of $27^{\circ} \mathrm{C}$ is actually allowed but only if it does not occur for more than 100 hours, i.e. about three working weeks. Once the clothing ensemble at which neutral thermal comfort could be achieved at each temperature had been determined, the subjects were instructed to wear that clothing during the experimental sessions. Photographs of each subject wearing each clothing ensemble were taken and sent to them just prior to each exposure to remind them of which clothing to wear. The average clothing insulation corresponded to 0.64 clo at $23^{\circ} \mathrm{C}$ and to 0.22 clo at $27^{\circ} \mathrm{C}$ which corresponds to PMV of -0.30 and 0.13 respectively assuming a metabolic rate of 1.2 met and 0.09 and 0.47 assuming a metabolic rate of 1.4 met.

The subjects were paid for participating in the experiment at a fixed rate per hour; they did not receive any bonuses related to their performance of the tasks. All subjects except one who missed one session completed both experimental repetitions.

\subsection{Measurements}

This article is protected by copyright. All rights reserved 


\section{Physical measurements.}

The temperature, relative humidity, and concentration of $\mathrm{CO}_{2}$ in the office were continuously recorded with $\mathrm{HOBO}$ data loggers at four workstations and at the centre of the room. The HOBO data loggers had a built-in temperature sensor (range: 0 to $+50^{\circ} \mathrm{C}$, accuracy: $\pm 0.2^{\circ} \mathrm{C}$ ) and a humidity sensor (range: 1-90\%, accuracy: $\pm 2 \%$ ); a $\mathrm{CO}_{2}$ sensor (range: 0 to $5000 \mathrm{ppm}$, accuracy: $\pm 50 \mathrm{ppm}$ ) was connected to the measurement input of the centrally-placed logger.

\section{Subjective measurements}

Subjects rated the conditions in the office, their environmental perceptions and the intensity of their acute subclinical health symptoms, their performance (SEPX) and their sleepiness (SLP). The questionnaires used were similar to those used by Lan et al. (2011a). Perceived Air Quality (PAQ) and thermal comfort were assessed using DTU continuous but split scales describing the acceptability of air quality, the acceptability of the thermal environment and their satisfaction with it $[25,26]$. The ASHRAE 7-point continuous scale was used to register thermal sensation [27]. The intensity of self-assessed acute subclinical health symptoms and willingness to perform work were rated using visual-analogue scales (VAS) - horizontal lines without graduation with two vertical dash lines marking the extreme points of the scale, each with end labels $[25,26]$. Subjects reported their self-estimated performance, the effort they exerted, and their attitude to work using VAS developed by Zhang et al. (2017b) [28]. Sleepiness was assessed using the 9-point verbally anchored Karolinska Sleepiness Scale with the following steps: extremely alert, alert, neither alert nor sleepy, sleepy but not fighting sleep, and very sleepy - fighting sleep [29]. These scales were presented to subjects on paper.

The subjects completed a questionnaire created by Yoshitake (1973) [30] to obtain their ratings of fatigue. It consisted of three groups of questions. Group I had ten questions describing 'drowsiness and dullness.' Group II had ten questions describing 'difficulty in concentration'. Group III had ten questions describing a 'lack of physical integration'. The questions in these three groups were presented to subjects in random order. The rate of complaints for all the participants was calculated for each group based on Yoshitake's method, and three types of fatigue were identified as defined by Yoshitake

This article is protected by copyright. All rights reserved 
(1973) [30]: general pattern of fatigue: "I > III > II", typical pattern of fatigue for mental work and overnight duty: "I > II > III", and typical pattern of physical work: "III > I > II", where I, II and III corresponds to the rate of complaints in the three groups defined above.

The NASA Task Load Index (TLX) for evaluating workload was derived using responses to a questionnaire described by Hart and Wickens (1990) [31]. It was determined from the responses on six linear scales (similar to VAS) describing "mental demand", "physical demand", "temporal demand", "performance", "stress", and "frustration level". The endpoints of the scales were marked low and high, except that in the case of performance (self-estimated performance of the tasks performed) they were marked poor and good (corresponding respectively to low and high). The overall mental workload (raw TLX) was calculated by averaging the scores on the six component scales, which were also analysed separately.

\section{Physiological measurements}

Skin temperature was measured continuously at left hand and temple at an interval of 1 min. "iButtons" (DS1923, USA, range: $-20^{\circ} \mathrm{C}$ to $+85^{\circ} \mathrm{C}$; accuracy: $\pm 0.1^{\circ} \mathrm{C}$; resolution: $0.5^{\circ} \mathrm{C}$ ) were used at the hand. "Pyrobuttons" (Pyrobutton-TH, USA, T: range: $-20^{\circ} \mathrm{C}$ to $+85^{\circ} \mathrm{C}$; accuracy: $\pm 0.3^{\circ} \mathrm{C}$; resolution: $0.0625^{\circ} \mathrm{C}$; $\mathrm{RH}$ : range: $3.4 \%$ to $97.3 \% \mathrm{RH}$; accuracy: $\pm 2.0 \% \mathrm{RH}$; resolution: $0.04 \% \mathrm{RH}$ ) were used at the temple. The measured relative humidity of skin was then used to calculate the skin absolute humidity [32]. These were wireless sensors attached to the skin by two layers of medical adhesive tape with good air permeability.

Heart rate and successive r-r intervals (the time interval between two heartbeats in milliseconds) were measured with a commercial heart rate monitor (Suunto Inc., Vantaa, Finland), which consisted of a chest strap with electrodes. Using a docking station, the heart rate and the $r-r$ interval data were later transferred to a computer for further analysis. pNN50, the percentage of successive heartbeat intervals that differed by more than 50 ms was then calculated. The pNN50 is a time-domain measure of heart rate variability (HRV) and is higher at higher levels of parasympathetic nervous system (PNS) activity

This article is protected by copyright. All rights reserved 
[33; higher PNS activity is a marker of lower stress and increased cognitive capacity $[34,35]$.

Respiration Rate (RR) in breaths per minute was monitored by a non-invasive capnography monitor (LifeSense LS1-9R; Nonin Medical Inc., USA, range: 3-80 breaths/minute, accuracy: 3 to 50 ( \pm 2 ) breaths/minute, 51 to $80( \pm 5)$ breaths/minute) that was used to obtain measurements of End-Tidal CO2 (EtCO2) using sidestream non-dispersive infrared spectroscopy (range: 0 to $99 \mathrm{mmHg}$, accuracy: \pm 2 $\mathrm{mmHg}$ ). Arterial blood oxygen saturation ( $\mathrm{SpO} 2)$ was measured with the same non-invasive monitor for pulse oximetry (LifeSense LS1-9R; Nonin Medical Inc., USA, range: 70-100\%, accuracy: $\pm 2 \%$ ) using a sensor attached to the subject's finger.

Alpha-amylase in the saliva was measured using a salivary amylase reagent apparatus (Nipro Inc., Japan, range: 10 to $200 \mathrm{kIU} / \mathrm{L}$, accuracy: $\pm 20 \%$ ). Each subject was asked to hold a reagent bar under the tongue for $30 \mathrm{sec}$. Then one side of the reagent bar, which collected the saliva, was inserted into the instrument for $1 \mathrm{~min}$, and after this time, the level of alpha-amylase was obtained. Subjects were asked not to eat or drink for half an hour prior to the collection of saliva. One subject was tested at a time. For healthy adults under no stress the salivary amylase value thus measured is less than 30 $\mathrm{kIU} / \mathrm{L} ; 31-45 \mathrm{kIU} / \mathrm{L}$ suggests a low level of stress, 46 to $60 \mathrm{kIU} / \mathrm{L}$ moderate stress, and higher levels indicate severe stress.

Samples of tear film mucus were taken. The subjects collected tear film mucus from the inside of the lower eyelid with a glass rod (while looking into a mirror) and deposited it onto a microscope slide. After drying the slide for 1 hour, the sample was classified under a microscope by three evaluators working independently, using five categories according to the closeness and branching frequency of the ferning patterns [36]. In Type I, the entire field of observation is full of uniformly branching fern-like crystallization patterns. In Type II, the frequency of branching is lower and some small empty spaces can be observed between the fern-like patterns. Type I and Type II quality of mucus indicate healthy and well-moisturised eyes. In Type III, large spaces without ferning are present in the field, single ferns are smaller compared with Type I and Type II and the branching is more like a "Christmas tree" or

This article is protected by copyright. All rights reserved 
"snow crystal" than "ferns". In Type IV, "Ferns" cannot not be recognized and tear mucus crystallization is poorly organized, indicating that the mucus would not be able to perform its function. In Type $V$, only clusters of mucus without any organized form are present, indicating the altered state of mucus crystallization that is typical for patients with dry eye syndrome.

\section{Measurement of performance}

The subjects performed tasks typical of office work and neurobehavioral tests; they were similar to those used by Lan et al. (2011a) [2]. The tasks typical of office work included text typing and addition. The neurobehavioral tests included five computerized tests presented to subjects in the following order: Mental reorientation (a spatial orientation test), Grammatical reasoning (a logical reasoning task), Digit span memory (a traditional test of verbal working memory), Number calculation (a mental arithmetical test in which the subject has to add and subtract two-digit numbers), Stroop (a test of the attentional focus and flexibility required to overcome perceptual/linguistic interference). Text typing, addition, Stroop, and Number Calculation were additionally presented to subjects with feedback about their performance, i.e. they could not continue until they corrected the error.

Speed (response time) and accuracy (\% of correct responses) were used as measures of performance in the tasks without feedback; speed (response time including the time spent for error correction) was used as a measure of the performance of tasks presented with feedback. For Digit span memory, the performance was in terms of accuracy (the maximum number of digits the subject could correctly learn and recall). In this case, a performance index (PI) was computed separately for each task to describe the mean processing/reaction time divided by the accuracy of responses.

Different versions of the Tsai-Partington test were used to assess changes in the level of arousal. All tasks except the Tsai-Partington test were presented on a computer screen and were self-paced; the computer clock recorded the reaction/processing time. The tasks were always performed in the same order independently of the condition. Four sets of tasks with a similar level of difficulty were prepared and randomly assigned to subjects in a design that was balanced for order of presentation as

This article is protected by copyright. All rights reserved 
described in the next paragraph.

\subsection{Experimental procedure}

The subjects were divided into two groups (Groups 1 and 2) of six persons each, with three females and three males in each group. Every group was exposed to each temperature twice in a repeated measured design balanced for the order of presentation as follows: Group 1: A-B-B-A and Group 2: B-A-A-B, where A was T23 and B, was T27. The experiments took place in two successive weeks in October 2018 from Monday to Thursday between 1:00 and 5:35 p.m.; subjects arrived about 15-20 min before each exposure. Each group was exposed twice a week: Group 1 was exposed on Mondays and Wednesdays, Group 2 on Tuesdays and Thursdays. Although only 12 subjects participated, the repeated measures design with repetition ensured that the statistical power of the study was similar to the statistical power of previous comparable studies on the effects of IEQ on performance in which 30 subjects were normally recruited, and the repeated measures design was used without repetition (e.g. [26]); the statistical power for both designs is 0.96 with the sphericity assumption and assuming equal medium effect size $(d=0.25)$ [37]. The same approach was used in the study by Lan et al. (2011a) [2] on which the present experiments were based and to which they are compared (see Discussion).

Figure 1 shows the schedule for each experimental session. Prior to entering the office, the subjects assembled in a waiting room (in which the temperature was about $22^{\circ} \mathrm{C}$ ) where they remained for approximately $15 \mathrm{~min}$. During this time, saliva samples were taken and tested. They also rated their willingness to perform work and reported their level of fatigue on the fatigue questionnaire with 30 questions. The instruments measuring their physiological reactions (heart rate monitor and iButtons) were attached; their heart rate and skin temperature were continuously recorded throughout the whole exposure. They adjusted their clothing if necessary and they were allowed to do so again at any time during the entire experimental session.

This article is protected by copyright. All rights reserved 
Exposure (heart rate and skin temperature were record continuously)
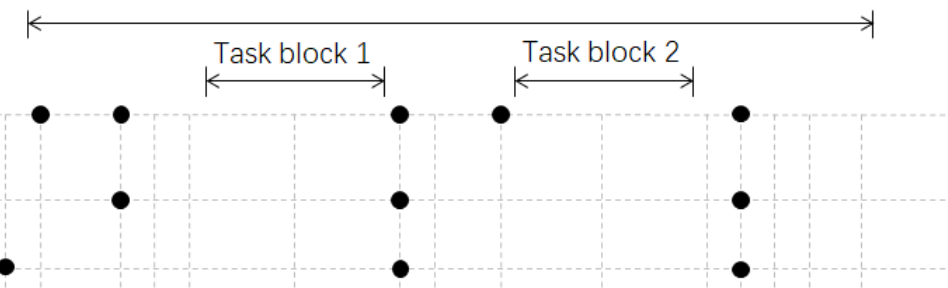

Thermal sensation and perceived

air quality assessment

Sleepiness assessment (SLP)

Fatigue assessment

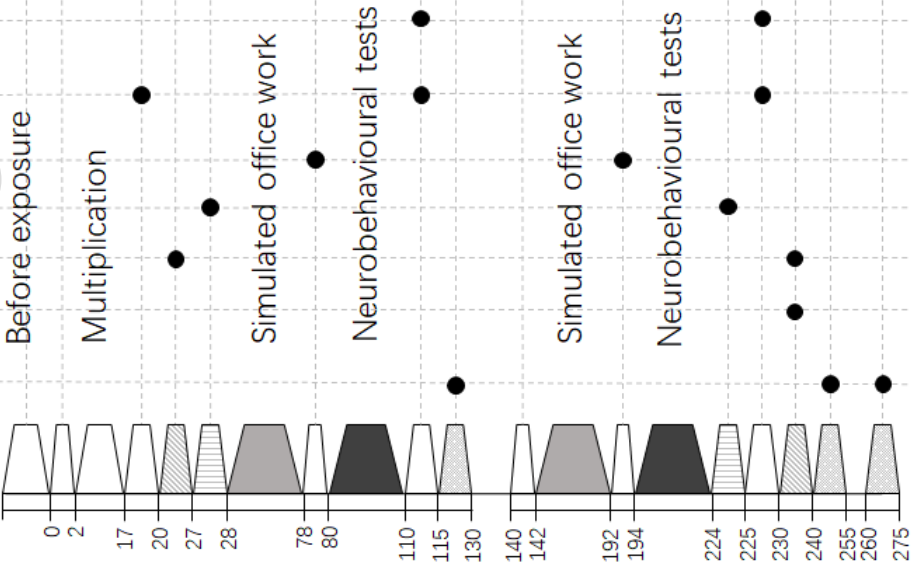

Self-estimated performance (SEPX)

Acute health symptoms and willingness

to perform work assessment

Workload assessment (NASA_TLX)

Tsai-Partington test

Saliva sampling

Tear sampling

End-tidal $\mathrm{CO}_{2}$ (EtCO2), oxygen

saturation (SpO2) and respiration

rate measurement

Figure 1 Experimental procedure

At around 1 p.m., the subjects entered the office, approached their workstations and immediately performed assessments of thermal comfort and air quality while standing. They then sat down and performed a multiplication task for $15 \mathrm{~min}$. This period was used to allow subjects to adapt to conditions in the office, so their results were not analysed. Once the multiplication task had been completed, the subjects assessed the air quality and their degree of thermal comfort, rated their sleepiness, the intensity of their acute subclinical health symptoms and willingness to perform work. A second saliva test followed these ratings. Subjects then performed a Tsai-Partington test followed by a period of 50 min during which they performed text typing (for $15 \mathrm{~min}$ ), addition (for $10 \mathrm{~min}$ ), text typing with feedback (for $15 \mathrm{~min}$ ), and addition with feedback for $10 \mathrm{~min}$. Upon completing these tasks, subjects evaluated their workload using the NASA-TLX, which was followed by a 30-min period during which they performed neurobehavioral tests with and without feedback. They then assessed air quality and their degree of thermal comfort, rated their sleepiness, fatigue, self-estimated performance, the intensity of acute subclinical health symptoms and willingness to perform work. This period was followed by a 10-min break during which the subjects could leave the office but were asked to stay inside the

This article is protected by copyright. All rights reserved 
building. After the break, the experimental program described above was repeated, this time without the initial multiplication task.

Towards the end of the exposure, after the subjects had completed all neurobehavioral tests with feedback, a Tsai-Partington test was performed, followed by assessments of air quality, thermal comfort, sleepiness, fatigue, self-estimated performance, the intensity of acute subclinical health symptoms and willingness to perform work. The subjects then took a tear sample and saliva tests were performed together with the measurements of EtCO2 and SpO2. After these measurements, the subjects remained in the office for 5 minutes without performing any tests or tasks - they were merely resting at the table. Once the 5-minute period was over, EtCO2 and SpO2 were again measured.

The subjects were instructed not to drink alcohol or overexert themselves on an experimental day or be late to bed on the day prior to each exposure.

All protocols were approved by the relevant Ethics Review Board and conformed to guidelines contained in the Declaration of Helsinki. Verbal and written informed consent was obtained from subjects prior to their participation in the experiment.

\subsection{Statistical analysis}

Analysis of variance (ANOVA) in a repeated measures design was applied to the results, using air temperature, elapsed time (or block of tasks, as indicated in Figure 1), and first or second exposure week as the three within-subject factors; Huynh-Feldt statistics was used to adjust the violation of sphericity. The significance level was set to be $0.05(P<0.05)$. The Cohen's effect size (d) was calculated as an indicator of whether the difference is of practical importance [37]. Effect sizes with values of $0.2,0.5$, and 0.8 indicate small, moderate, and large changes [38].

\section{Results}

This article is protected by copyright. All rights reserved 


\subsection{Physical parameters}

The average values of the physical parameters describing the indoor environment in the office are shown in Figure 2. Average temperatures were $23.2 \pm 0.2^{\circ} \mathrm{C}$ and $27.4 \pm 0.2^{\circ} \mathrm{C}$ at $\mathrm{T} 23$ and $\mathrm{T} 27$ respectively, and as shown in Figure 2, they were quite stable. Relative humidity was systematically but only slightly higher at $\mathrm{T} 23$, as expected. It averaged $\sim 42 \%$ at this temperature and $\sim 38 \%$ at $\mathrm{T} 27$. The concentration of $\mathrm{CO}_{2}$ was systematically higher at T27 even though the ventilation rate was the same under each condition; the system was set to supply outdoor air at $10 \mathrm{~L} / \mathrm{s}$ per person. The difference in the measured $\mathrm{CO}_{2}$ concentration was up to $100 \mathrm{ppm}$ and increased towards the second part of each exposure. In both temperature conditions, $\mathrm{CO}_{2}$ was below 1,000 ppm.

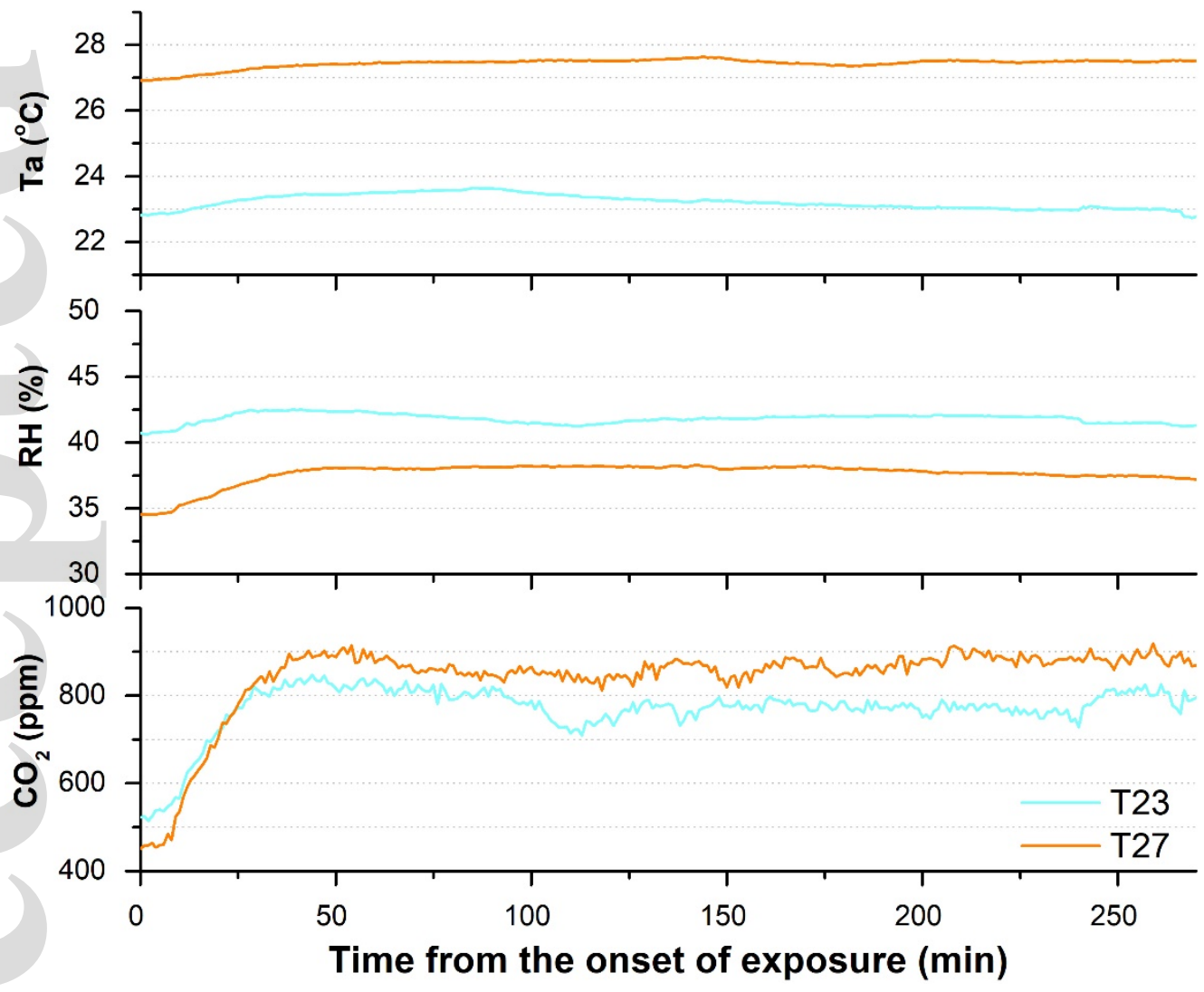

Figure 2. Physical measurements of $\mathrm{Ta}, \mathrm{RH}$ and $\mathrm{ppm} \mathrm{CO}_{2}$ in the office environment under the two temperature conditions

This article is protected by copyright. All rights reserved 


\subsection{Subjective ratings}

\section{Thermal comfort}

The subjects were close to neutral thermal comfort at both T23 and T27 as the average thermal sensation votes (TSV) were all in the range from -0.5 to 0.5 . However, they were slightly cool at T23 (TSV between $0.05 \pm 0.53$ and $-0.51 \pm 0.65$ ) and slightly warm at T27 (TSV between $0.35 \pm 0.46$ and $0.48 \pm 0.42$ ), Figure 3 . This difference was systematic and statistically significant. At both temperature conditions they assessed the thermal environment to be acceptable although they rated the acceptability as slightly higher at T23 (acceptability between $0.51 \pm 0.34$ and $0.76 \pm 0.23$ ) than at T27 (acceptability between $0.42 \pm 0.35$ and $0.55 \pm 0.28$ ). As can be seen in the Supplementary Material (Table S1), this difference was statistically significant only during the first part of the exposure (until 110 minutes from the onset of an exposure). No significant interaction effects between temperature and elapsed time were observed.

This article is protected by copyright. All rights reserved 


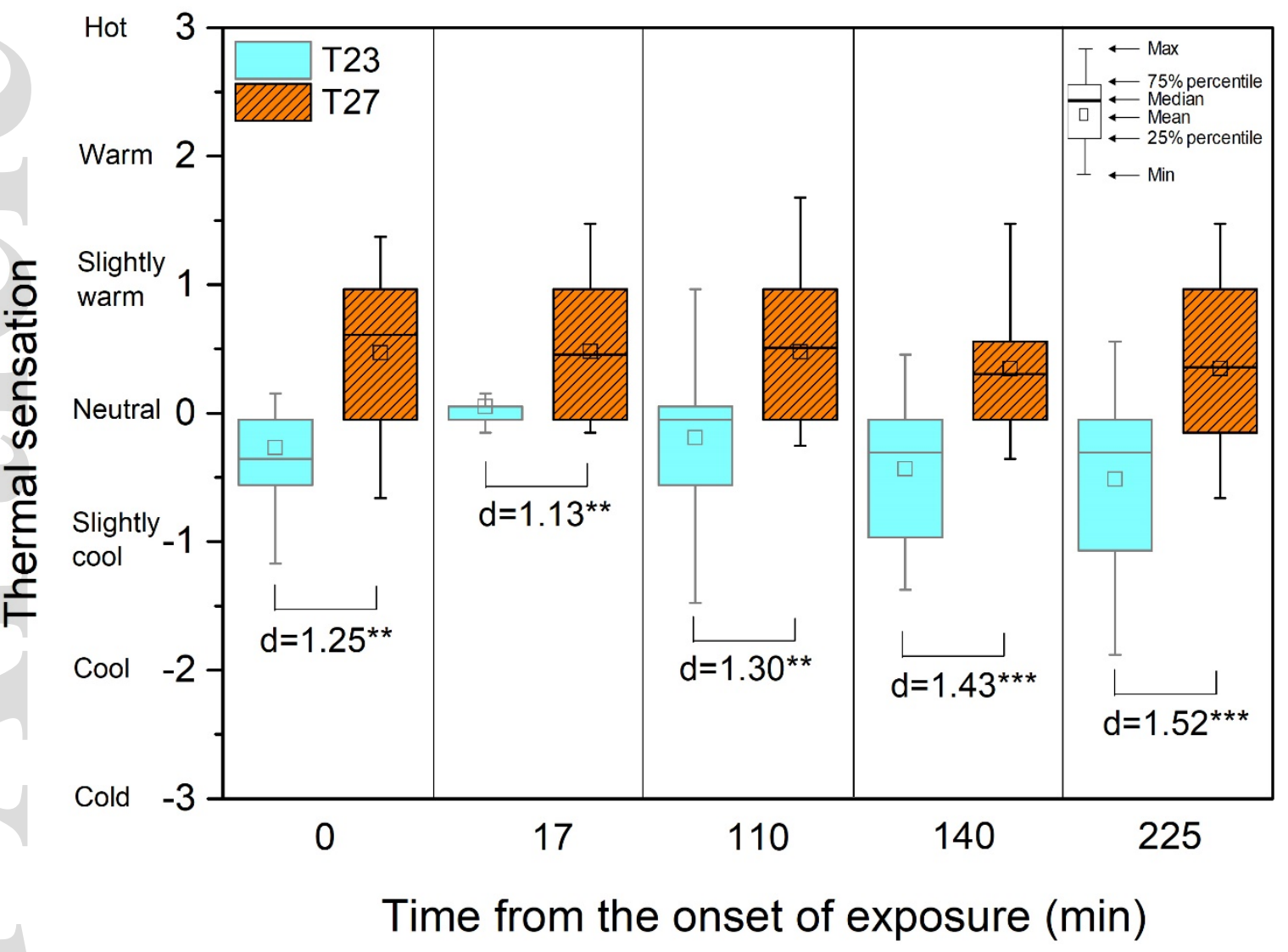

Figure 3. Thermal sensation votes of subjects at two temperature conditions $\left({ }^{* *} \mathrm{P}<0.001,{ }^{* *} \mathrm{P}<0.01\right.$, d-Cohen's effect size)

\section{Perceived air quality}

Subjective ratings of air quality show that it was assessed as acceptable under both temperature conditions (Figure 4); the estimated percentage dissatisfied with air quality was below 10\% (see Supplementary Material, Table S2, [39]). The acceptability of air quality at T23 $(0.56 \pm 0.34$ to $0.74 \pm 0.25)$ was systematically higher than at T27 $(0.40 \pm 0.30$ to $0.51 \pm 0.43)$ and the difference was statistically significant during the first part of the exposure (until 110 minutes from the onset of an exposure), after which the difference between conditions was not statistically significant. The acceptability of the air quality decreased in the course of the experiment under both temperature conditions. Odour intensity was rated to be lower than "slight", and it was systematically lower at T23 (see Supplementary Material, Table S2) although the difference was statistically significant only at the beginning of the exposure (until 17 minutes from the onset of each exposure). The intensity of irritation 
of eyes, nose and throat was rated to be very low, far below "slight" and generally did not differ between the two temperature conditions (see Supplementary Material, Table S2). The subjects perceived the air quality as less acceptable and odour intensity and the irritation of the eyes and throat increased with longer exposure time $(P<0.05)$. No other significant effects were observed.

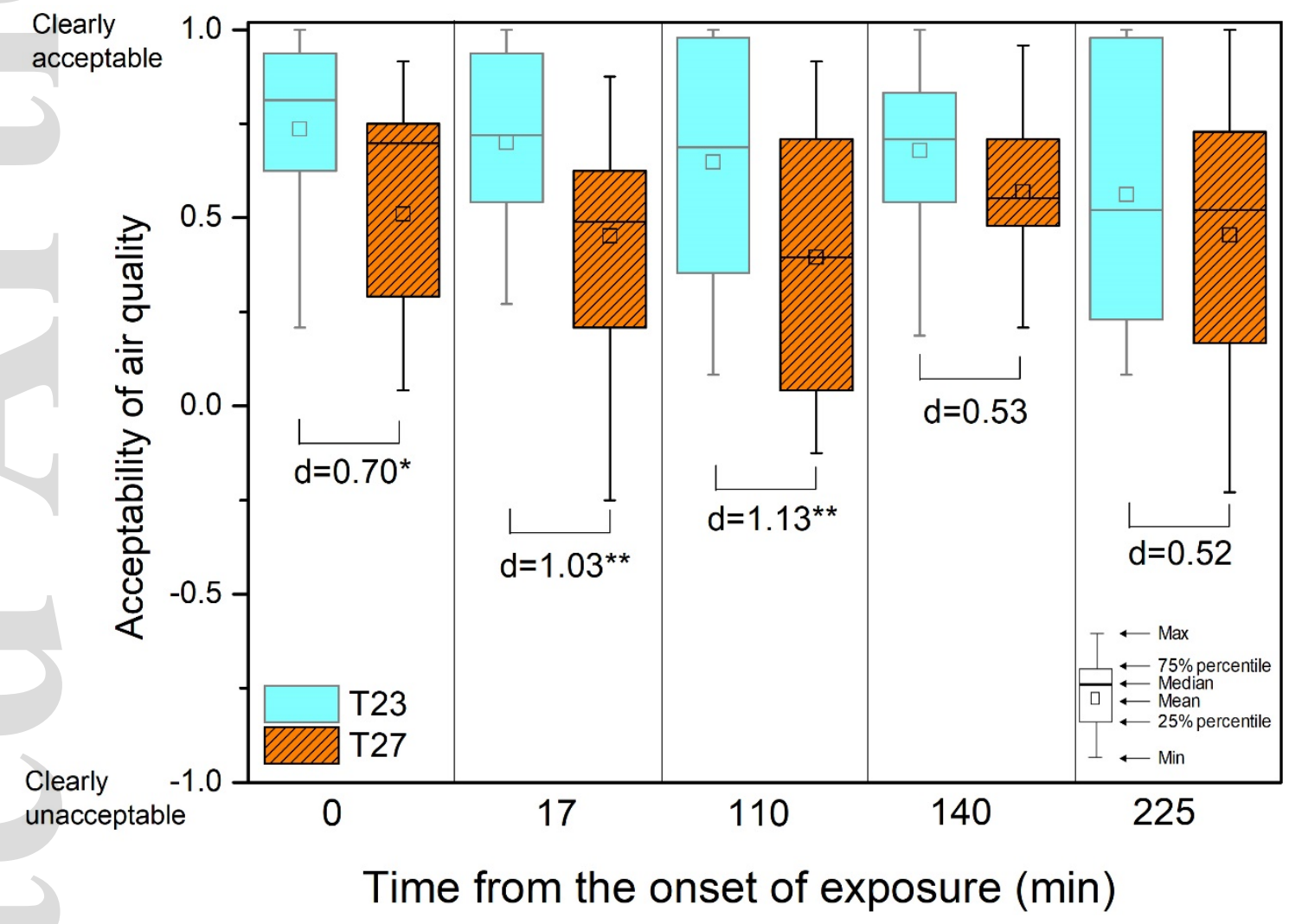

Figure 4. Ratings of acceptability of air quality at two temperature conditions $\left({ }^{* *} P<0.01,{ }^{*} P<0.05\right.$, d-Cohen's effect size).

Figure 5 shows that the ratings of acceptability of the air quality were strongly correlated with the ratings of the acceptability of the thermal environment, but they were not correlated with the thermal sensation votes.

This article is protected by copyright. All rights reserved 

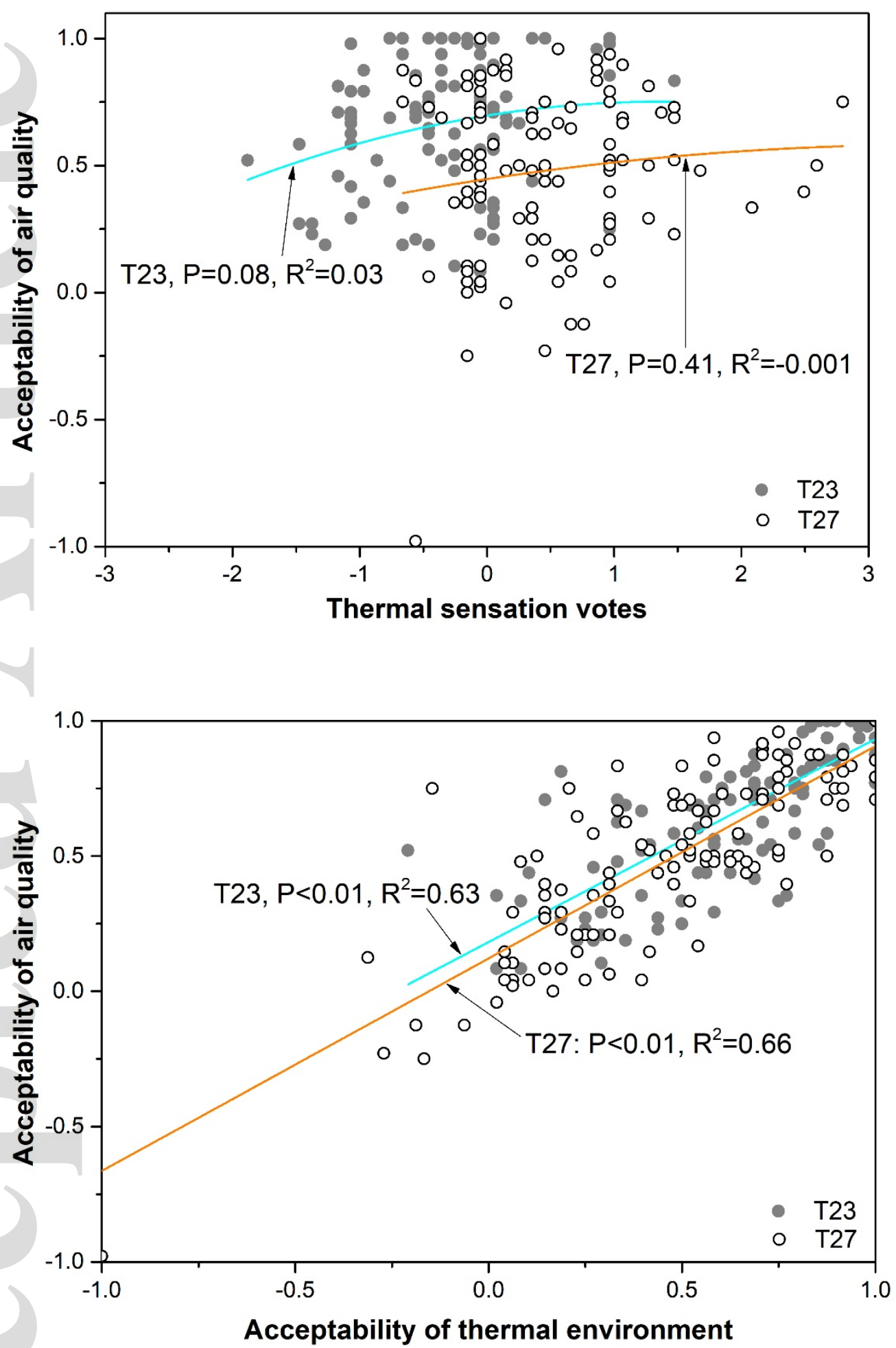

Figure 5. Ratings of acceptability of air quality as a function of thermal sensation votes (top) and acceptability with the thermal environment (bottom)

Figure 6 shows whether the subjects rated the air during the experiments as fresh or stuffy; the air in 
the T27 condition was rated to be significantly more stuffy (see Supplementary Material, Table S3). No significant effect of exposure time was observed.

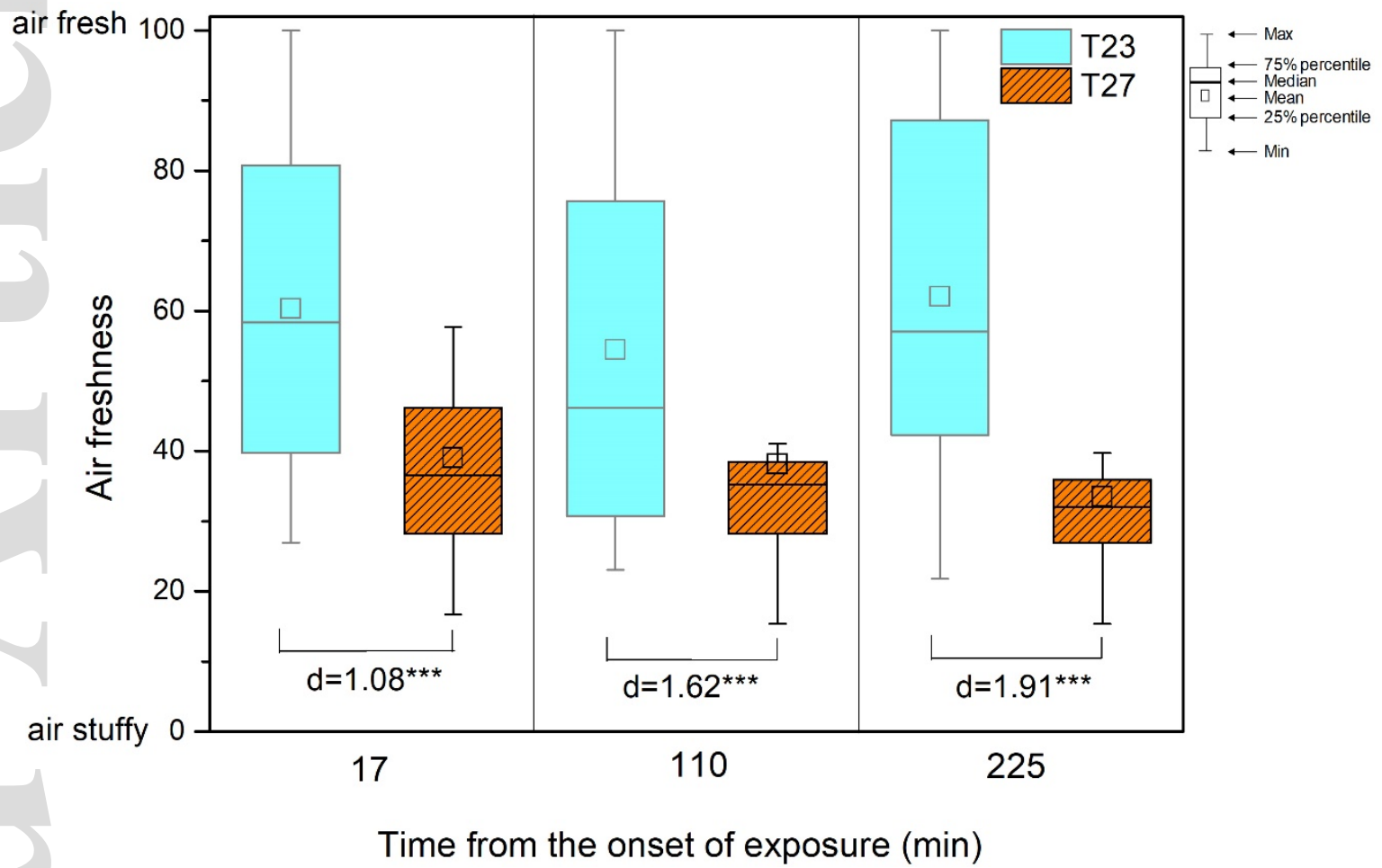

Figure 6. Subjective ratings indicating whether the air was perceived to be fresh or stuffy under the two temperature conditions $\left({ }^{* * *} \mathrm{P}<0.001\right.$, d-Cohen's effect size)

\section{Acute subclinical health symptoms}

Subjects reported being more tired in the T27 condition and with longer exposure time (Figure 7). This is consistent with their assessments of the intensity of their acute subclinical health symptoms (see Supplementary Material, Table S3). The order of the level of different types of fatigue indicates that it was typical for fatigue due to mental work under both temperature conditions (Figure 7).

This article is protected by copyright. All rights reserved 


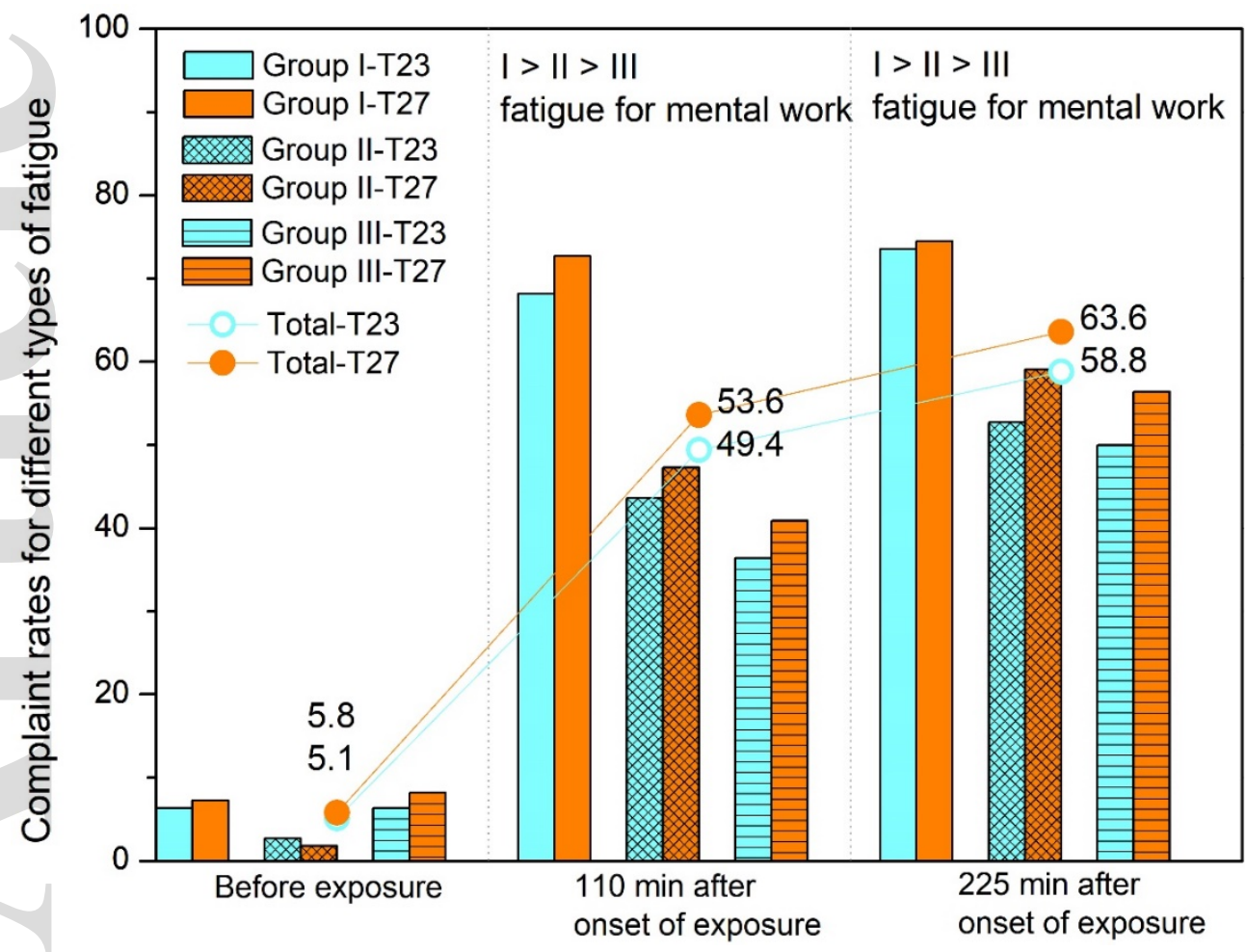

Figure 7 . The ratings of fatigue in the course of the exposure

Apart from the differences in fatigue, the intensity of acute subclinical health symptoms reported by the subjects did not differ significantly between the two temperature conditions (see Supplementary Material, Table S3). For the following symptoms, the size of the difference between conditions estimated using Cohen's d was close to moderate: the subjects indicated that the air was slightly drier in the T27 condition but only at the end of exposure (time from the onset was $225 \mathrm{~min}$, Supplementary Material, Table S3); their mouth and throat were rated drier in the T27 condition. The rated intensity of many acute subclinical health symptoms, including dry throat, mouth and eyes, aching eyes, headache, difficult to think, dizzy, feeling bad, tired, hard to concentrate, depression and sleepy were all significantly higher towards the end of the exposure $(P<0.05)$. No other significant effects were observed.

\section{Work load and self-estimated performance}

Figure 8 summarizes the ratings used to derive the NASA-TLX index at the two different temperatures.

This article is protected by copyright. All rights reserved 
Subjects rated their mental and temporal demand, their level of stress and their overall workload significantly higher at the end of their exposure to T27 $(P<0.05)$. No statistically significant difference was observed for these ratings at the beginning of the exposure or for ratings of physical demand, performance or frustration. No significant effects of exposure time or significant interaction effects of temperature and exposure time were observed on mental workload.

Time from the onset of exposure ( $\mathrm{min})$

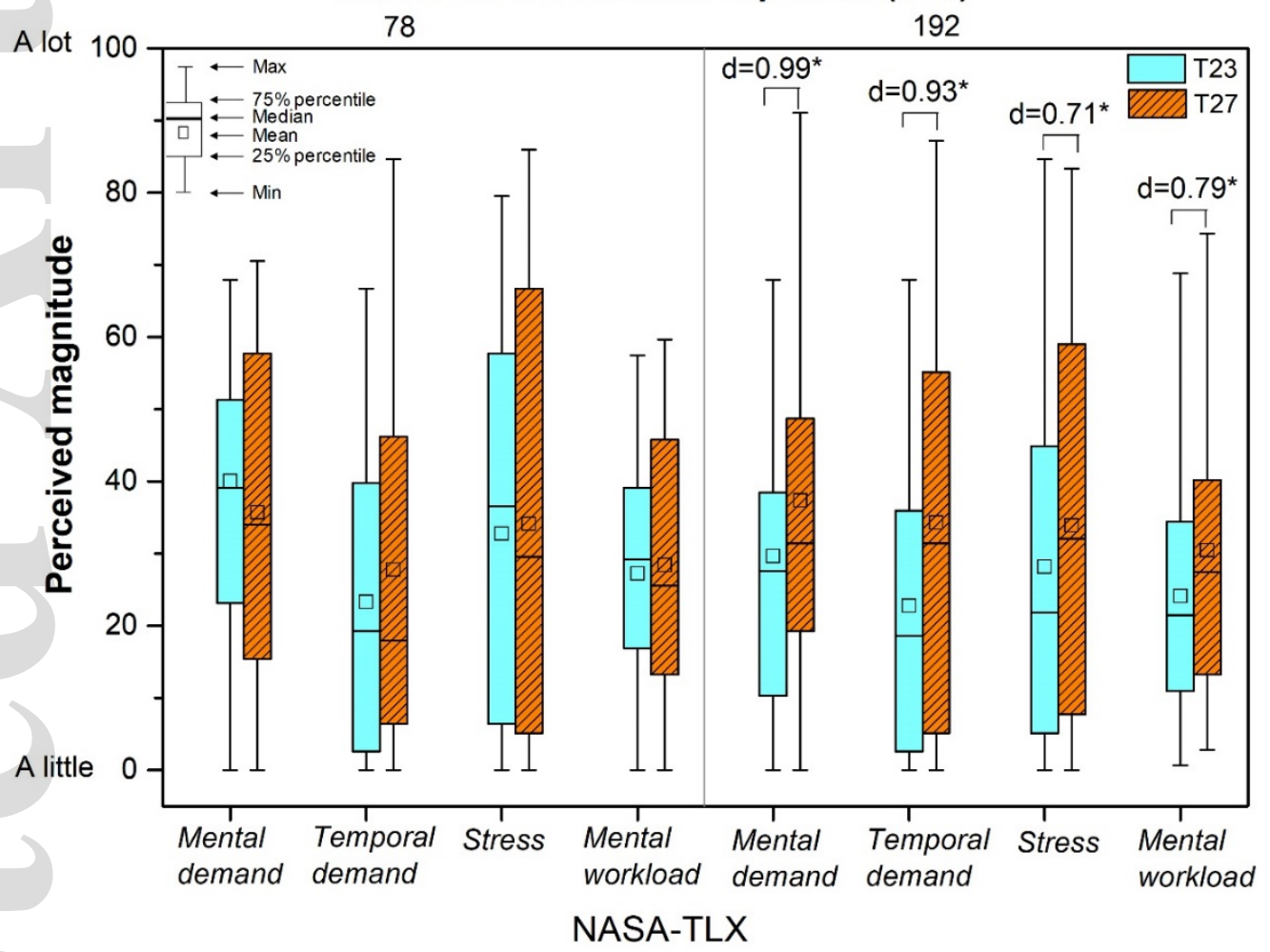

Figure 8 Mental workload (Raw TLX) and the component scales of NASA-TLX during the course of the exposures to the two temperature conditions ( ${ }^{*} \mathrm{P}<0.05$, d-Cohen's effect size)

Figure 9 shows that the subjects' willingness to perform work decreased during the course of the experiment $(P<0.001)$; it was higher at T23 compared with T27 (moderate effect size), although this difference was not statistically significant. Self-estimated performance was higher at T23 and this was significant at the end of the exposure $(P<0.05$, Figure 9$)$. No significant difference between conditions in terms of rated sleepiness (SLP) or other items used to monitor self-estimated performance (SEPX) was observed (see Supplementary Material, Table S4). However, the average intensity of sleepiness, 
task demand, exerted effort, and time pressure were all higher in the T27 condition.
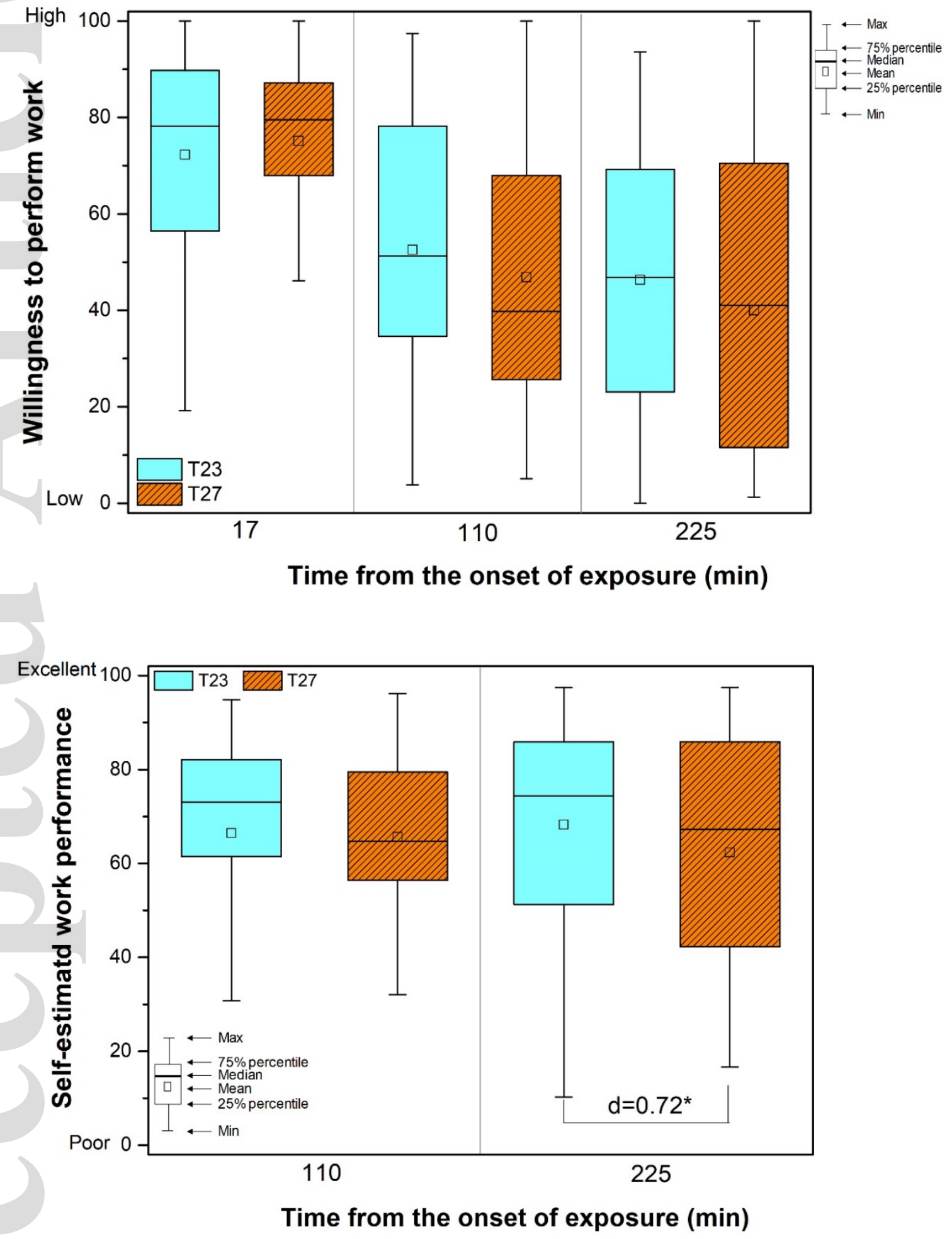

Figure 9. Willingness to perform work (top) and self-estimated work performance (bottom) in the two temperature conditions ( ${ }^{*} \mathrm{P}<0.05$, d-Cohen's effect size) 


\subsection{Cognitive performance}

Among the tasks and tests used to examine cognitive performance only the performance of a Tsai Partington test, typing and the Stroop test without feedback were significantly different between the two temperature conditions examined (Table 1). Subjects made more correct connections in the Tsai-Partington test $(P<0.01)$, typed more characters $(P<0.001)$ and solved more units in the Stroop test $(\mathrm{P}<0.05)$ in the T23 condition. The size of the difference in the performance of the grammatical reasoning and Stroop with feedback tests was moderate at this temperature. For the remaining tests, no statistically significant or meaningful differences in performance were observed. Except for the performance of three neurobehavioral tests (Digit Span, Numerical Calculation with and without Feedback), the performance of other tests and tasks improved during the second part of experiments after the break (block 2) compared with performance before the break (block 1$)(P<0.05)$. The results in Table 1 show the average performance of the two times (block 1 and block 2 ) when the tasks typical of office work and the neurobehavioral tests were completed by the subjects.

Table 1. Performance of tasks typical of office work and of the neurobehavioral tests; a negative relative change in the performance index $(\triangle)$ indicates that performance decreased at T27 compared with T23

\begin{tabular}{|c|c|c|c|c|c|c|}
\hline \multirow[b]{2}{*}{ Task or test } & \multirow[b]{2}{*}{ Metrics $^{\dagger}$} & \multicolumn{2}{|c|}{ Value (Mean $\pm S D$ ) } & \multirow{2}{*}{$\begin{array}{l}\text { Difference in } \\
\text { performance } \\
(\triangle)\end{array}$} & \multirow{2}{*}{$\begin{array}{l}\text { Cohen's } \\
\text { effect } \\
\text { size (d) }\end{array}$} & \multirow{2}{*}{$\begin{array}{l}\text { Statistica } \\
\text { difference } \\
\text { (P) }\end{array}$} \\
\hline & & T23 & T27 & & & \\
\hline Tsai-Partington & $\begin{array}{l}\text { Correct } \\
\text { number }\end{array}$ & $17.5 \pm 2.1$ & $16.2 \pm 2.6$ & $-7.5 \%$ & 1.32 & $0.002^{* *}$ \\
\hline Typing & Chars/min & $196 \pm 70$ & $184 \pm 65$ & $-6.0 \%$ & 1.78 & $<0.001^{* * *}$ \\
\hline $\begin{array}{l}\text { Typing with } \\
\text { feedback }\end{array}$ & Units/min & $188 \pm 67$ & $190 \pm 65$ & $0.9 \%$ & 0.14 & 0.68 \\
\hline
\end{tabular}

This article is protected by copyright. All rights reserved 


\begin{tabular}{lllllll}
\hline Calculation & Units/min & $5.07 \pm 1.36$ & $5.11 \pm 1.34$ & $0.9 \%$ & 0.10 & 0.77 \\
Calculation with & Units/min & $5.20 \pm 1.49$ & $5.24 \pm 1.48$ & $0.6 \%$ & 0.09 & 0.79 \\
feedback & & & & & & \\
Redirection & Units/min & $0.87 \pm 0.28$ & $0.86 \pm 0.29$ & $-0.9 \%$ & 0.11 & 0.72 \\
Grammatical & Units/sec & $0.20 \pm 0.09$ & $0.18 \pm 0.05$ & $-11.2 \%$ & $\mathbf{0 . 4 9}$ & 0.15 \\
Reasoning & & & & & & \\
Digit Span & Span & $7.33 \pm 1.27$ & $7.13 \pm 1.53$ & $-2.8 \%$ & 0.22 & 0.50 \\
Number & Units/sec & $0.41 \pm 0.08$ & $0.41 \pm 0.09$ & $-0.2 \%$ & 0.03 & 0.93 \\
Calculation & & & & & & \\
Numerical & Units/sec & $0.42 \pm 0.08$ & $0.41 \pm 0.08$ & $-1.3 \%$ & 0.17 & 0.60 \\
Calculation with & & & & & & \\
Feedback & & & & & & \\
Stroop & Units/sec & $0.51 \pm 0.12$ & $0.47 \pm 0.12$ & $-8.2 \%$ & $\mathbf{0 . 7 3}$ & $\mathbf{0 . 0 4}$ \\
Stroop with & Units/sec & $0.54 \pm 0.14$ & $0.51 \pm 0.11$ & $-6.0 \%$ & 0.17 \\
Feedback & & & & & & \\
\hline
\end{tabular}

†Performance index shown in the table is correct number per minute or second of each task;

${ }^{* * *} \mathrm{P}<0.001,{ }^{* *} \mathrm{P}<0.01,{ }^{*} \mathrm{P}<0.05$

\subsection{Physiological responses}

The skin temperature at the temple was systematically higher at T27 (average $35.0 \pm 0.4^{\circ} \mathrm{C}$ ) than at T23 (average $\left.34.0 \pm 0.6^{\circ} \mathrm{C}\right)(P<0.001, d=2.55)$ (Supplementary Material, Figure $\left.\mathrm{S} 1\right)$. The skin temperatures at the hand were also systematically higher at T27 (average $33.8 \pm 1.0^{\circ} \mathrm{C}$ ) than at T23 (average $\left.31.4 \pm 1.6^{\circ} \mathrm{C}\right)(P<0.001, \mathrm{~d}=4.84)$ (Supplementary Material, Figure $\left.\mathrm{S} 1\right)$. It should be noted that skin temperature at T27 was reasonably stable during the experiments and only slightly lower during the second part of the exposure, whereas skin temperature at T23 was noticeably lower in the second part of the exposure. Thermal sensation votes (Figure 3) reflected this difference between conditions but not the change over time. Thermal Sensation Votes (TSV) reported during the exposure and the 
10-min skin temperature averaged around each TSV assessment were linearly correlated at T23 but not at T27 (Figure 10): this indicates that heat balance was regulated by (easily perceived) changes in vasodilation at T23 and by (unperceived) changes in the rate of evaporation of sweat at T27.

The skin absolute humidity measured on the temple was the same at T23 and T27 at the beginning of the exposure and then it gradually increased, more at T27 than at T23, stabilising during the course of exposure (Supplementary Material, Figure S2). Towards the end of the exposure the skin absolute humidity was higher at T27 (average $\left.30.1 \pm 7.2 \mathrm{~g} / \mathrm{m}^{3}\right)$ than at T23 (average $\left.27.1 \pm 6.9 \mathrm{~g} / \mathrm{m}^{3}\right)(P=0.067$, $d=0.65$ ). The higher skin absolute humidity at T27 confirms that the rate of evaporation of sweat from the skin was higher at T27 than at T23, as the room absolute humidity was the same at both temperatures.

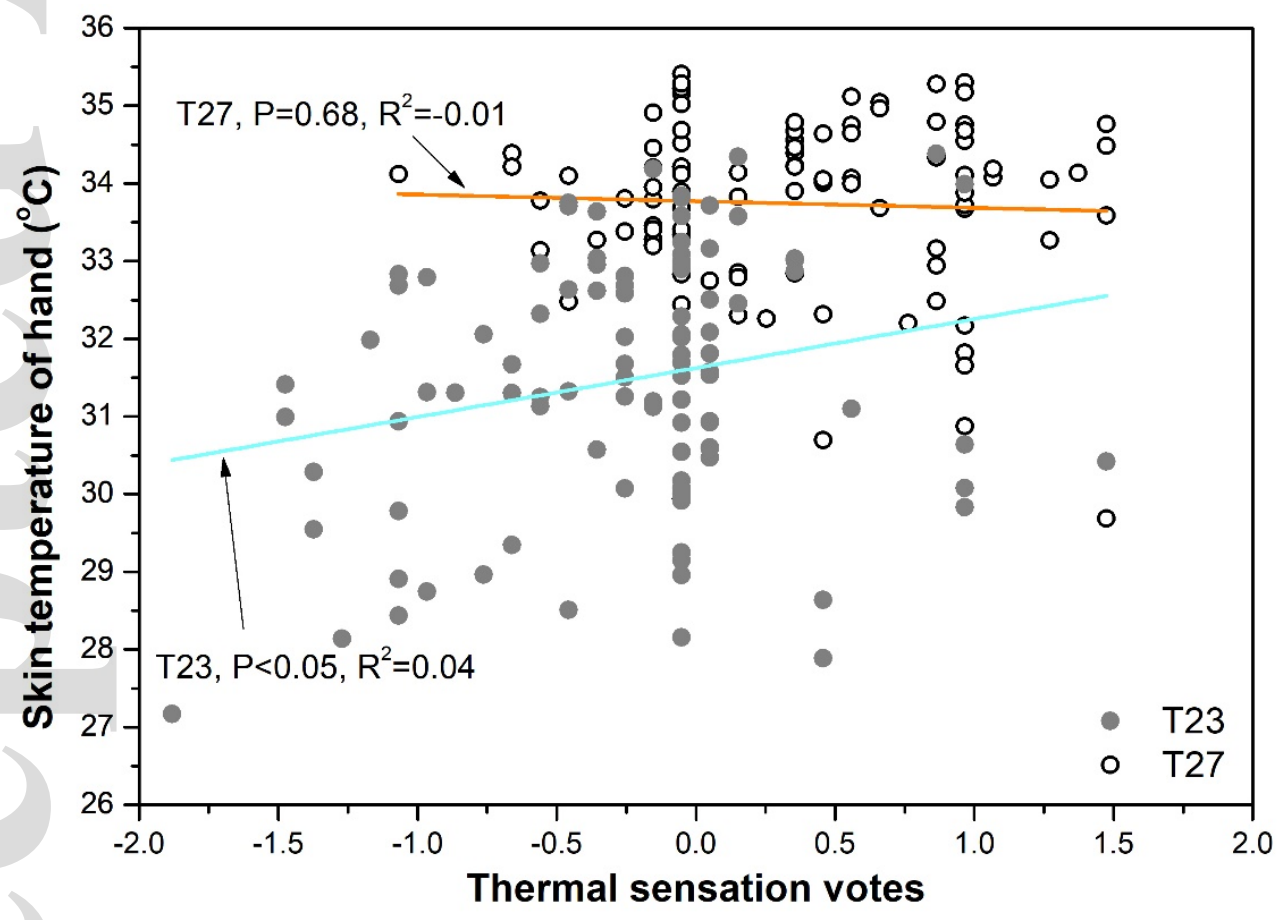

This article is protected by copyright. All rights reserved 


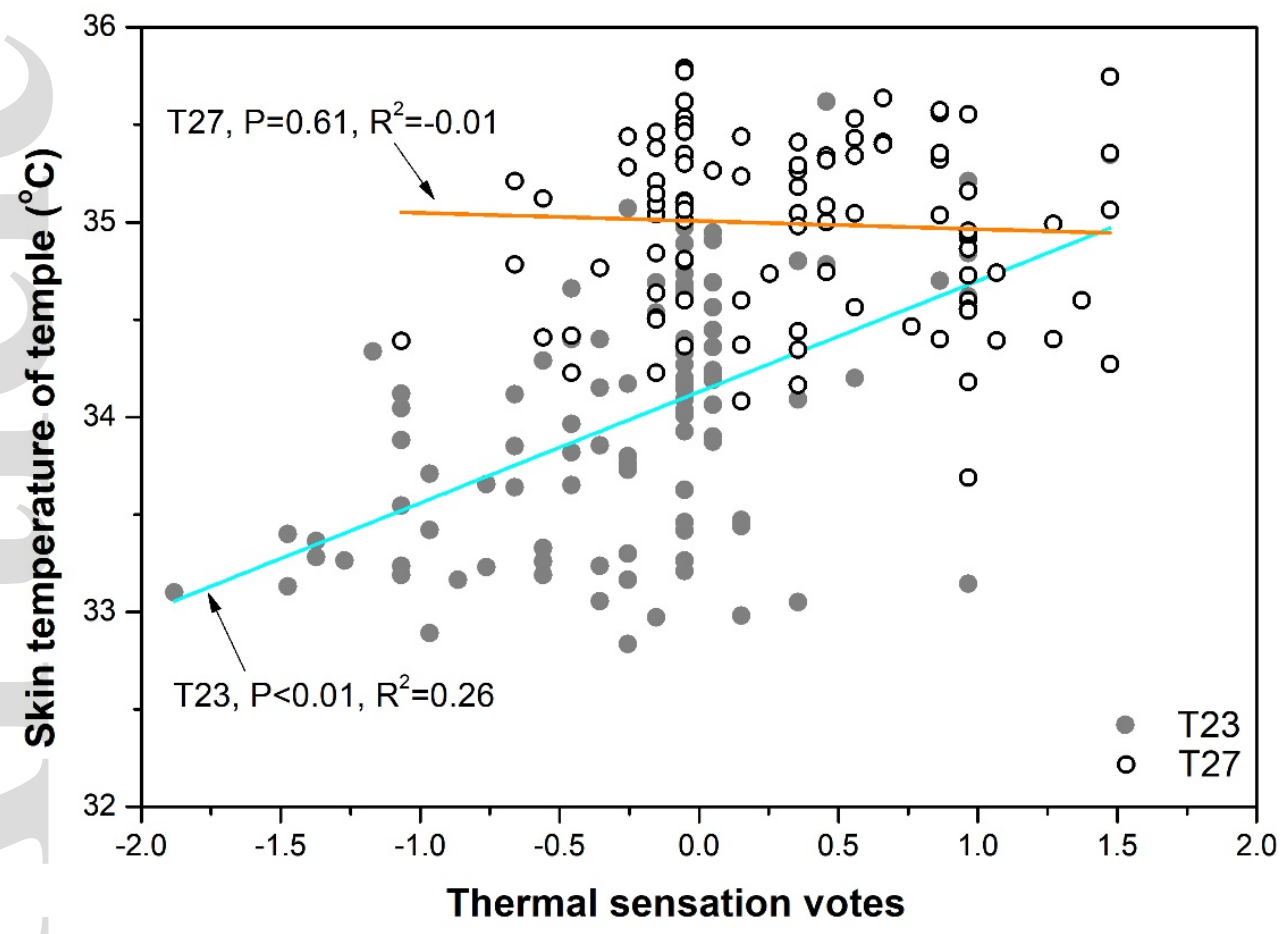

Figure 10. The relationship between thermal sensation vote and skin temperature of the hand (top) and the temple (bottom) at the two temperature conditions. Data points from T27 are shown with open circles.

Figure 11 shows that the heart rate was slightly higher $(P<0.001)$ and the proportion of successive heartbeat intervals that differed by more than $50 \mathrm{~ms}$ ( $\mathrm{pNN50)}$ was lower at T27 $(\mathrm{P}<0.01)$. This indicates that subjects were under more stress in this condition and is consistent with the results of the Tsai-Partington test (Table 1) which is a cue-utilization test and can be considered as an indicator of arousal/stress. However, no differences were observed between the two temperature conditions in the alpha-amylase levels measured in saliva (see Supplementary Material, Table S5). A higher heart rate may also imply a higher metabolic rate as a response to elevated temperature levels.

This article is protected by copyright. All rights reserved 


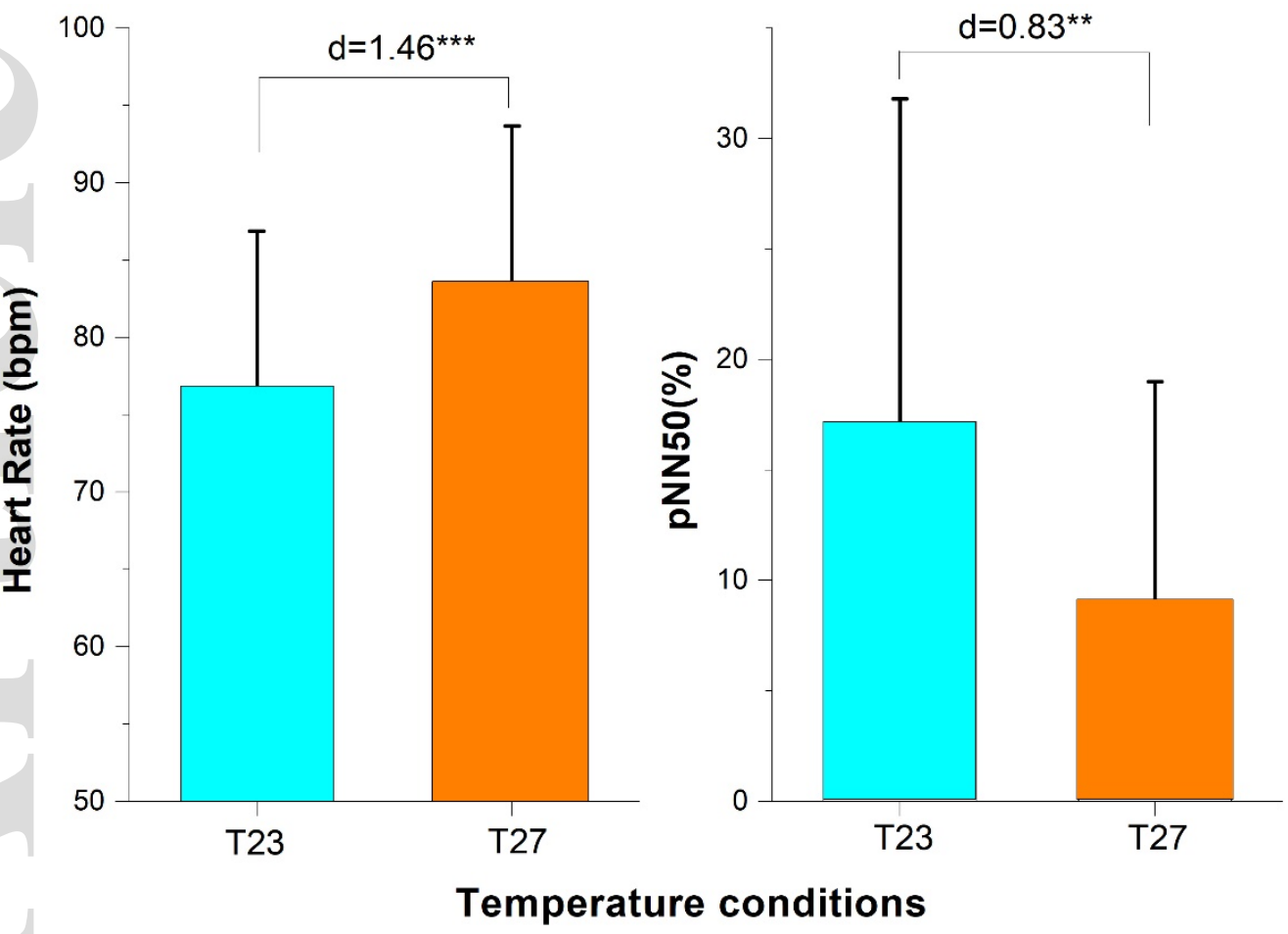

Figure 11 Average heart rate (HR, left) and pNN50 (right) in the two temperature conditions (*** $P<0.001,{ }^{*} \mathrm{P}<0.01$, d-Cohen's effect size; Error bars represent the standard deviation of the mean)

Arterial oxygen saturation was lower in the T27 condition (Figure 12). The difference was significant and much larger towards the end of each exposure and was caused by an increase in SpO2 over time in the T23 condition. The measured respiration rate was always higher at T27 than at T23, but a statistically significant difference could only be shown at the end of the second task block (Figure 12). This is consistent with the slightly higher $\mathrm{CO}_{2}$ concentration measured at T27 (Figure 2). No useable EtCO2 measurements were obtained due to a malfunctioning instrument.

This article is protected by copyright. All rights reserved 


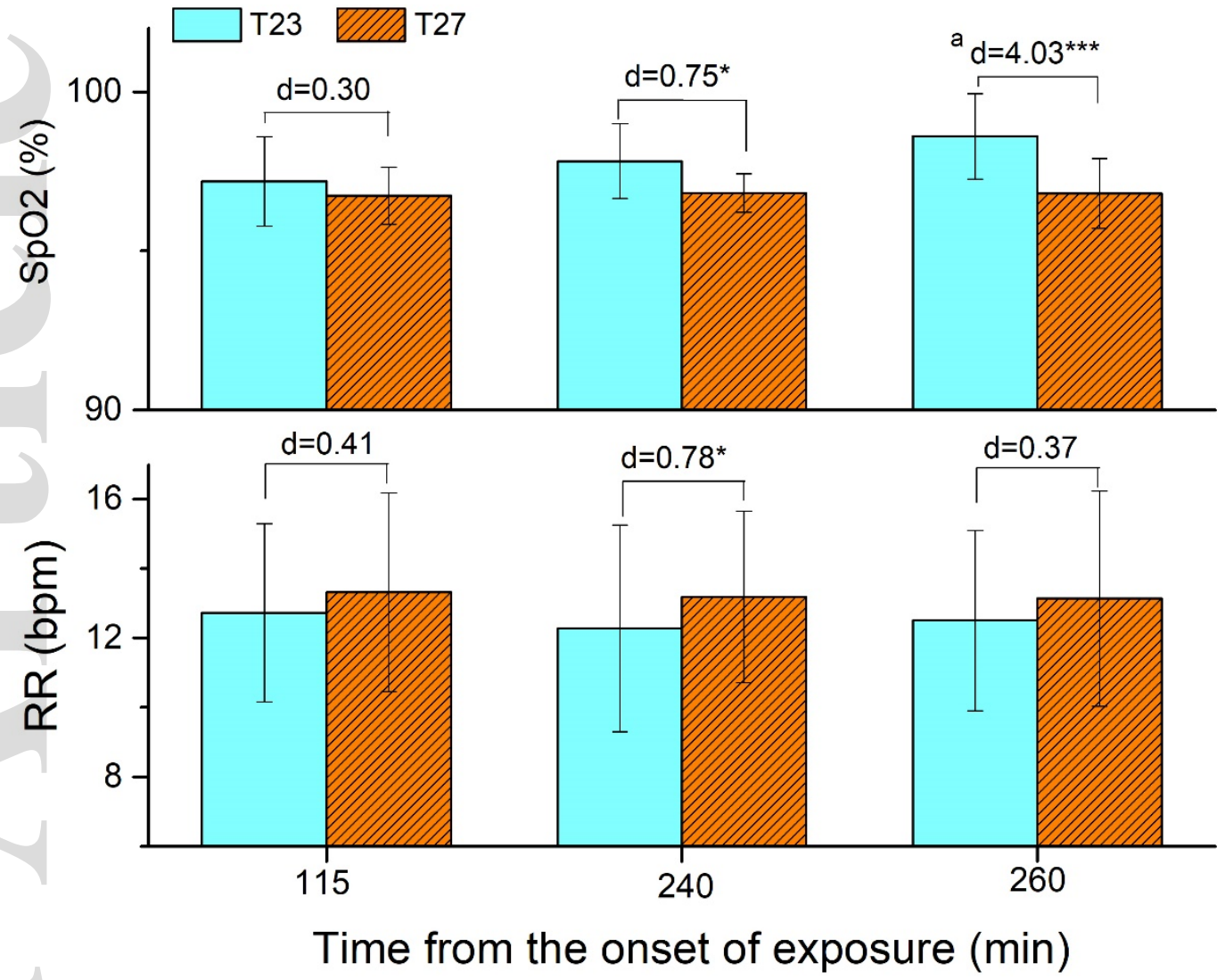

Figure 12 Arterial oxygen saturation (SpO2, top) and respiration rate (RR, bottom) measured at the two temperature conditions; error bars represent the standard deviation of the mean. a denotes that the SpO2 of 5 subjects were presented due to missing data ${ }^{* * *} P<0.001,{ }^{*} P<0.05$, d-Cohen's effect size; Error bars represent the standard deviation of the mean).

Observations of Type I and II quality of tear film (indicating good tear film mucus quality) were more frequent at T23, and observations of Type III and IV (indicating poor tear film mucus quality) were more frequent at T27; the difference was not statistically significant, although the effect size was moderate $(P=0.35, d=0.35)$ (Supplementary Material, Figure S3).

\section{Discussion}

The present study examined human responses at two temperatures, one a temperature that is typically preferred indoors $\left(23^{\circ} \mathrm{C}\right.$ labelled as T23) and the other a moderately elevated temperature $\left(27^{\circ} \mathrm{C}\right.$ 
labelled as T27). At both temperatures, the subjects were able to adjust their clothing insulation so that they could maintain a state of neutral thermal comfort. The purpose was to examine whether any effects on acute subclinical health symptoms or cognitive performance would be caused by the physiological changes induced by moderately increased temperature, in the absence of thermal discomfort. It is often assumed that there will be no such effects. Wyon et al. (1975) performed a comparable study of the performance of subjects clothed for comfort in the range of temperatures up to $23^{\circ} \mathrm{C}$, comparing a moderately reduced temperature $\left(18^{\circ} \mathrm{C}\right)$ with $23^{\circ} \mathrm{C}[21]$. As in the present experiment, their subjects were in a state of neutral thermal comfort at both temperatures. These authors could not show any differences in cognitive performance between $18^{\circ} \mathrm{C}$ and $23^{\circ} \mathrm{C}$. They concluded that reducing the temperature from $23^{\circ} \mathrm{C}$ to $18^{\circ} \mathrm{C}$ while remaining thermally comfortable by increasing clothing insulation would not cause negative effects on performance.

The present study can be seen as an extension of the findings of Wyon et al. (1975) [21] to moderately elevated temperatures. The lower temperature (T23) was the same as the higher temperature in the study reported by Wyon et al. (1975) [21] and the higher temperature (T27) was only just above the thermal comfort range prescribed by current standards for buildings with mechanical cooling [18]. The present experiment examined not only effects on cognitive performance but also physiological responses, subjective ratings of the acceptability of the environment and the intensity of acute subclinical health symptoms. The results show that maintaining a state of neutral thermal comfort does not prevent the occurrence of negative effects on performance when room temperature is increased above the conventional range for thermal comfort. The most likely explanation for this is that unwanted physiological responses inevitably take place as a result of elevated temperature. These changes cause increased stress, fatigue and perceived mental workload, changes that could logically contribute to the observed negative effects on performance, while the perception that the air quality was reduced at T27 may have had a negative psychological effect. These effects were not caused by changes in acute subclinical health symptoms as no such changes were reported by the subjects when the temperature was increased. The present results suggest that the absence of thermal discomfort at elevated temperatures does not guarantee that there will be no effects on cognitive performance. Wyon

This article is protected by copyright. All rights reserved 
et al. (1975) showed that moderately reduced temperatures did not produce such effects in the absence of thermal discomfort [21], but it would clearly be unwise to assume that this absence of an effect on cognitive performance could be extrapolated to temperatures above $23^{\circ} \mathrm{C}$. The upper and lower temperature levels that do not cause negative effects on cognitive performance will have to be determined using larger numbers of subjects than in the present experiment and that of Wyon et al. [21], before any generalizations can be made.

The present results provide additional insights into the findings reported by Lan et al. (2011a) [2]. In their study, the subjects experienced two temperature levels, one at which they were thermally comfortable $\left(22^{\circ} \mathrm{C}\right)$ and the other at which they reported discomfort due to warmth $\left(30^{\circ} \mathrm{C}\right)$. This study could not show whether the observed effects were caused by thermal discomfort, by elevated temperature, or by both thermal discomfort and elevated temperature. The present results suggest that the effects observed in the earlier study should not be attributed to thermal discomfort alone. Table 2 compares the results from both studies and it may be seen that the results were similar: the air quality was perceived as poorer, subjectively rated fatigue and mental workload increased, performance decreased, skin temperature, heart rate, and respiration rate were all higher while blood oxygen concentration $(\mathrm{SpO} 2)$ and heart rate variability pNN50 were lower when the temperature was raised (due to a malfunctioning instrument, no EtCO2 values were available in the present work). There was one important difference between the results obtained in these two studies. In the present experiment, no difference between conditions was found in the ratings of experienced acute subclinical health symptoms while a difference was clearly seen in the study of Lan et al. (2011a) [2]. Since the higher temperature $\left(27^{\circ} \mathrm{C}\right)$ in the present study was lower than that $\left(30^{\circ} \mathrm{C}\right)$ in the study of Lan et al. (2011a) [2], it is possible that the intensity of acute subclinical health symptoms may start to increase somewhere between $27^{\circ} \mathrm{C}$ and $30^{\circ} \mathrm{C}$. However, by wearing lighter clothing, the subjects dissipated more heat to the environment in the present study and thus maintained thermal comfort. It may thus be that it was thermal discomfort that caused subjects to complain of acute subclinical health symptoms at $30^{\circ} \mathrm{C}$, i.e. that it was a subjective "reverse halo effect". Further studies are needed to confirm this interpretation.

This article is protected by copyright. All rights reserved 
In both the present study and the Lan et al. (2011a) [2] study, the subjects rated the acceptability of air quality as lower and the air as "more stuffy" at the higher temperature. This is consistent with other studies showing that increased temperatures reduce perceived air quality even when the pollution loads and ventilation rates remain unchanged (e.g., [40]). Whether the perception of reduced air quality as a result of increased temperature contributes to reduced cognitive performance will have to be determined in the future. The present results do not provide an answer to this question, although it is possible that some physiological reactions, such as the observed changes in respiration rate, could have occurred because subjects perceived the air quality to be poorer. Fang et al. (1998) hypothesized that reduced air quality at increased temperature is due to the reduced cooling effect of warm inhaled air on the nasal mucosa [41]. If so, physiological responses are possible as the effect is not purely psychological. On the other hand, the results of Fang et al. (2002) suggest that poor perceived air quality caused by increased temperature does not reduce cognitive performance [5]. Fang et al. (2002) exposed subjects to different levels of temperature and relative humidity at which subjects felt thermally neutral and did not observe any differences in cognitive performance between the different conditions, although the intensity of headaches and fatigue increased significantly in the $26^{\circ} \mathrm{C}-60 \%$ condition, which was the highest temperature and relative humidity combination in their study, and this led them to suggest that during longer exposures or at higher temperatures, some negative effects on cognitive performance would be likely. The results of the present study seem to confirm this expectation.

Table 2 Comparison of results obtained in the present experiment and the study of Lan et al. (2011a) [2]

\section{Contents Results reported by Lan et al. (2011a) Results obtained in the present study}

Thermal Two air temperatures: $22^{\circ} \mathrm{C}$ vs. $30^{\circ} \mathrm{C} \quad$ Two air temperatures: $23^{\circ} \mathrm{C}$ vs. $27^{\circ} \mathrm{C}$;

environment Clothing: a constant 0.9 clo Clothing was adjusted to maintain a state of neutral thermal comfort (0.64 clo at $23^{\circ} \mathrm{C}$ and 0.22 clo at $27^{\circ} \mathrm{C}$ )

Perception Thermally neutral at $22^{\circ} \mathrm{C}$ and warm at Close to thermally neutral at $23^{\circ} \mathrm{C}$ and 
of the

environment The perceived air quality was worse at $30^{\circ} \mathrm{C}$

Acute

subclinical

health

symptoms

Fatigue

NASA-TLX

Workload

Task

performance

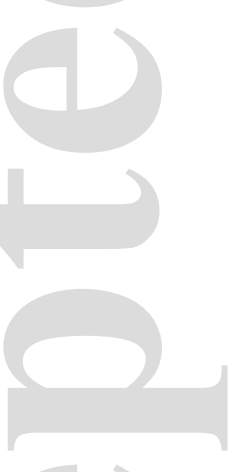

Physiological

responses
The intensity of acute subclinical health

symptoms, including dry throat, dry

mouth, difficult to concentrate, feeling

bad, tired, hard to think, and feeling

depressed, increased at $30^{\circ} \mathrm{C}$

Fatigue increased by more than $20 \%$ at $30^{\circ} \mathrm{C}$

The perceived workload increased at $30^{\circ} \mathrm{C}$, with an effect size of about 0.7

A significant decrease in task

performance was observed at $30^{\circ} \mathrm{C}$ for addition with or without feedback, Stroop with or without feedback, grammatical reasoning, and visual reaction time task; the maximum decrease was $25 \%$. The subjects were less willing to exert effort while working and reported lower self-estimated performance

Skin temperature, heart rate, respiration rate, and EtCO2 concentration increased, and $\mathrm{SpO} 2$ concentration and tear film quality decreased at $30^{\circ} \mathrm{C}$ No effects on the concentration of salivary alpha-amylase and cortisol were

\section{$27^{\circ} \mathrm{C}$}

The perceived air quality was worse at $27^{\circ} \mathrm{C}$

No significant difference was observed in most acute subclinical health symptoms, although the subjects felt more tired at $27^{\circ} \mathrm{C}$ toward the end of exposure

Fatigue increased by about $10 \%$ at $27^{\circ} \mathrm{C}$ The perceived workload increased at $27^{\circ} \mathrm{C}$ with a similar effect size but only toward the second half of exposure. A significant decrease in task performance was observed at $27^{\circ} \mathrm{C}$ for Tsai-Partington, typing, and Stroop; the maximum decrease was $11.2 \%$. No significant change in willingness to exert effort was observed; self-estimated performance was significantly lower at $27^{\circ} \mathrm{C}$ towards the end of each exposure

Skin temperature, heart rate, and respiration rate increased, and pNN50 and $\mathrm{SpO} 2$ concentration decreased at $27^{\circ} \mathrm{C}$ No effect was observed on salivary alpha-amylase. EtCO2 concentration

This article is protected by copyright. All rights reserved 
The decreased performance and increased mental workload suggest that even moderately elevated temperatures should be avoided. In the present study, a similar magnitude of change in workload between the two air temperatures was observed as in the study of Lan et al. (2011a) [2] although the decrease in performance was smaller. Abbasi et al. (2019) observed that a $1^{\circ} \mathrm{C}$ increase in temperature above the comfortable temperature of $22^{\circ} \mathrm{C}$ caused about a $1.4 \%$ change in the workload [3]. Maula et al. (2016) showed that slightly warm temperatures caused concentration difficulties and decreased the performance of a working memory task [42]. Geng et al. (2017) showed that optimal performance could be expected when people feel thermally neutral or slightly cool [9]. In a 12-day follow up study, Cedeño-Laurent et al. (2018) observed decreased performance of cognitive tasks in a non-airconditioned (NAC) group (mean indoor temperature: $26.3^{\circ} \mathrm{C}$; $\mathrm{SD}=2.5^{\circ} \mathrm{C}$; range $=19.6-30.4^{\circ} \mathrm{C}$ ) compared with the $\mathrm{AC}$ group (mean $=21.4^{\circ} \mathrm{C} ; \mathrm{SD}=1.9^{\circ} \mathrm{C}$; range $=17.5-25.0^{\circ} \mathrm{C}$ ) [43]. They described the performance of the Stroop task by a U-shaped curved with linear effects below and above an optimum range of indoor temperature $\left(22^{\circ} \mathrm{C}-23^{\circ} \mathrm{C}\right)$. This is consistent with the relationship developed by Lan et al. (2011b) [7], Seppänen et al. (2006) [6] and Wargocki et al. (2019) [12] who all found that lower temperatures are more favourable for performance. This conclusion was supported by the findings of Lee et al. (2012) [44], who assessed attention by measuring brain waves and found an increase at a lower temperature $\left(20.5^{\circ} \mathrm{C}\right)$ compared with a thermally comfortable temperature $\left(24.0^{\circ} \mathrm{C}\right)$ in an indicator of selective attention, suggesting that lower temperatures are more favourable for the selective attention required for optimal performance. Zhang et al. (2017a) compared performance at $22^{\circ} \mathrm{C}$ and $25^{\circ} \mathrm{C}$ and did not find any effect but this may have been because the temperature of $25^{\circ} \mathrm{C}$ was always encountered after the lower temperature, so learning could have compensated for any negative effect [22].

The effects in the present experiment were observed at a temperature of $27^{\circ} \mathrm{C}$, which is just outside the thermal comfort zone prescribed by existing standards $[17,18]$ and higher than the lowest 
recommended set point for cooling ventilation in China [45], which is $26^{\circ} \mathrm{C}$. The subjects participating in the present experiment were Caucasian and acclimatized to temperate climate conditions.

Experiments were performed in the fall of 2018 only a few months after one of the hottest summers ever recorded in Denmark, during which temperatures had reached $30^{\circ} \mathrm{C}$ and above for extended periods. Whether similar effects are to be expected at lower temperatures for people acclimatized to cold climates and at higher temperatures for people acclimatized to higher temperatures will have to be examined in the future, but it should be noted that in a recent study reported by Fan et al. (2019) [46], subjects acclimatized to a subtropical humid climate (Changsha, China) were thermally neutral at $26^{\circ} \mathrm{C}$ and felt slightly warm at $30^{\circ} \mathrm{C}$ and $33^{\circ} \mathrm{C}$, at which temperatures they rated the environment as not thermally comfortable. The performance of a Tsai-Partington test was reduced at $30^{\circ} \mathrm{C}$ but no other results regarding cognitive performance were indicated. They reported a systematically increasing intensity of acute subclinical health symptoms as temperatures increased from $26^{\circ} \mathrm{C}$ to $37^{\circ} \mathrm{C}$. Whether acclimatization to higher temperatures will result in no negative consequences in the form of reduced performance or increased intensity of subclinical health symptoms should be investigated with high priority in the near future, as global temperatures are currently increasing year by year due to the accumulation of greenhouse gases in the atmosphere.

The temperature at which negative effects on performance occur may depend on the physiological capacity of the body to deal with elevated temperatures, even when thermal discomfort is avoided. For this reason, the elderly or people with compromised physiological systems, e.g., those having cardiovascular diseases or respiratory problems, may be at risk. For these groups, temperatures should probably be maintained at moderate levels to reduce the stress on their physiological system. More experiments with different populations of subjects are required to support or reject this recommendation.

The higher skin temperatures at the temple and hand and the higher heart rate indicate that the subjects experienced more active thermoregulation at $27^{\circ} \mathrm{C}$ compared with $23^{\circ} \mathrm{C}$. A small amount of active thermoregulation for a short period may have benefits for health [47], but the consequences of

This article is protected by copyright. All rights reserved 
sustaining thermoregulation over long periods remain unclear. The increased respiration rate and the lower arterial oxygen saturation $(\mathrm{SpO} 2)$ toward the end of the exposure to $27^{\circ} \mathrm{C}$ suggest that a long period of exposure to elevated temperature will bring about physiological responses that can potentially reduce performance, as low oxygen saturation is associated with decreased cognitive function $[48,49]$. Brain activity consumes $20-30 \%$ of all energy produced in the body and in the process of providing cells with energy, oxygen is consumed [50]. It has also been shown, using brain imaging techniques, that the brain increases its uptake of oxygen (and glucose) into active brain areas during cognitively demanding tasks [48]. Decreased pNN50 at $27^{\circ} \mathrm{C}$ compared with $23^{\circ} \mathrm{C}$ indicates that changes in the parasympathetic nervous system (PNS) activity have taken place, as pNN50, a time-domain measure of heart rate variability, is closely correlated with PNS activity, higher pNN50 indicating higher PNS activity [33]. Several studies have reported that stress was significantly associated with reduced PNS activity and lower pNN50 [51,52]. Hammel et al. (2011) found that worry was associated with significantly decreased PNS activity and suggested a linkage between autonomic and cognitive inflexibility [53]. The neurovisceral integration theory postulates that raised PNS activity indicates increased cognitive capacity and is critical for higher-order behaviour and cognition $[34,35]$. pNN50 can be calculated from successive $r-r$ intervals of heart rate, which is usually provided by a portable heart rate monitor such as a chest belt used in the present experiment, thus allowing convenient calculation of HRV. However, more studies are required to validate the reliability of the time-domain measure of HRV in indoor environmental exposures.

No effect of room temperature on the level of salivary alpha-amylase in saliva was observed, neither in the present study nor in the study of Lan et al. (2011a) [2] (Table 2). The low level of salivary amylase (less than $30 \mathrm{kIU} / \mathrm{L}$ ) indicates that the subjects were not experiencing any pressure.

A slightly higher $\mathrm{CO}_{2}$ level in room air at $27^{\circ} \mathrm{C}$ in the present experiment indicates increased physiological activity. Although there were no changes in the outdoor air supply rate of $10 \mathrm{~L} / \mathrm{s}$ per person, the concentration of $\mathrm{CO}_{2}$ was $100 \mathrm{ppm}$ higher at $27^{\circ} \mathrm{C}$ than it was at $23^{\circ} \mathrm{C}$. Similar findings were observed in the previous study (Lan et al., 2011a): the indoor $\mathrm{CO}_{2}$ concentration at $22^{\circ} \mathrm{C}$ was $801 \mathrm{ppm}$,

This article is protected by copyright. All rights reserved 
which was the same as was observed at $23^{\circ} \mathrm{C}$ in the present study (in both experiments the outdoor air supply rate per person was the same), and it increased to $1047 \mathrm{ppm}$ at $30^{\circ} \mathrm{C}$, i.e., to a higher level than the $900 \mathrm{ppm}$ at $27^{\circ} \mathrm{C}$ in the present study. This increase seems likely to be due to an increased metabolic rate (as is also indicated by the increased heart rate at higher temperatures observed in these two studies) while attempting to maintain performance and increased physiological activity in response to the negative effects of increased temperature. Studies of $\mathrm{CO}_{2}$ emission from humans at elevated temperatures and different metabolic activity would be useful.

The skin temperature of hand and temple and thermal sensation were slightly correlated at T23 but not at T27 (Figure 10), possibly because the whole-body thermoregulation was achieved mainly by vasodilation at T23 and mainly by thermally induced sweating at T27; this conjecture is supported by the results of measurements of skin humidity (Figure S2, Supplementary Material). Witterseh et al. (2004) observed some forehead sweating on $4 \%, 36 \%$ and $76 \%$ of subjects at $22^{\circ} \mathrm{C}, 26^{\circ} \mathrm{C}$ and $30^{\circ} \mathrm{C}$ when clothing was not adjusted adaptively between conditions [54], and although $36 \%$ were observed to be sweating at $26^{\circ} \mathrm{C}$ when clothed so as to remain thermally comfortable at $22^{\circ} \mathrm{C}$, only $21 \%$ of them felt warm at $26^{\circ} \mathrm{C}$, most probably due to the evaporative heat loss. The small difference in skin relative humidity observed in the present study (Figure S2, Supplementary Material) makes it clear that $27^{\circ} \mathrm{C}$ was only just warm enough to induce sweating, supporting the subjects' subjective reports that at this temperature they were still thermally comfortable. It is however remarkable that this temperature was sufficient to produce a measurable negative effect on performance.

A limitation of the present results is that subjects reported feeling slightly above neutral thermal comfort (slightly warm) at $27^{\circ} \mathrm{C}$ and slightly below neutral thermal comfort (slightly cool) at $23^{\circ} \mathrm{C}$. This difference was systematic and statistically significant. However, the difference was within the range of -0.5 to 0.5 on the 7-point ASHRAE scale that is generally considered to indicate neutral thermal comfort. The acceptability of the thermal environment as rated by the subjects was slightly lower at $27^{\circ} \mathrm{C}$ than it was at $23^{\circ} \mathrm{C}$, and this difference was systematic and significant. These differences, albeit very small, could contribute to the observed effects on performance but it is difficult to predict to what extent. They do

This article is protected by copyright. All rights reserved 
show, however, that even when people are close to or at thermal neutrality, lower temperatures lead to better performance. This is consistent, as mentioned earlier, with the relationships developed by Seppänen et al. (2005) [6], Lan et al. (2011b) [7] and Wargocki et al. (2019) [12]. That lower temperatures are conducive to improved performance for tropically acclimatized subjects was shown by Tham (2004) [14] for office workers in a call centre in Singapore and by Porras-Salazar et al. (2018) [55] for pupils in an elementary school in Costa Rica. The mechanism by which lower temperatures are beneficial should be investigated in the future but the present study suggests that this may be the result of lower stress on the physiological thermal regulation system. The present study shows that temperature and thermal discomfort should be treated separately and not interchangeably and that both must be optimized to provide conditions supporting comfort, health, and cognitive performance. However, the subjects of the present study were Caucasian, all young and resident in Denmark. The same experimental protocol should be replicated using subjects with different thermal experience and different age.

One important implication of the present work is that even though adjusting clothing at elevated temperatures can reduce and even eliminate thermal discomfort, this does not guarantee that there will be no negative effects on cognitive performance. This means that setting thermostats on the basis of thermal comfort alone might lead to economic losses due to reduced performance.

Whether there are any other negative effects of elevated temperature beside those observed in the present study must be investigated further. One important area is sleep quality. Lan et al. (2017) discussed thermal conditions for sleep, and avoiding elevated temperatures seems to be important for ensuring high sleep quality and optimal next-day performance [56]. The optimal temperature for sleep has yet to be determined.

\section{Conclusions}

By adjusting their clothing insulation, subjects succeeded in achieving a state of neutral thermal

This article is protected by copyright. All rights reserved 
comfort at both $23^{\circ} \mathrm{C}$ and $27^{\circ} \mathrm{C}$, although they rated the acceptability of the thermal environment as higher at $23^{\circ} \mathrm{C}$ and perceived air quality was better at this temperature. No significant changes in acute subclinical health symptoms were observed. The perceived mental workload increased and measured work performance decreased significantly at $27^{\circ} \mathrm{C}$. These effects were accompanied by many physiological changes, including increased skin temperature and humidity, heart rate and respiration rate and decreased pNN50 (a measure of parasympathetic nervous system activity) and arterial oxygen saturation (SpO2). No change in salivary alpha-amylase was found at this temperature. The present results suggest that a moderately elevated room temperature reduces cognitive performance even when people report that they are thermally comfortable. Changes in physiological responses are believed to cause this reduction. These findings should be carefully considered when prescribing room temperatures in workplaces to avoid economic loss caused by reduced work performance.

\section{Acknowledgment}

This work was supported by a research grant from the Bjarne Saxhof Foundation to Dr. Pawel Wargocki, and by grants from the National Natural Science Foundation of China (Nos. 51778359 and $51478260)$.

\section{References}

[1] Lan, L., Lian, Z.W. and Pan, L. (2010). The effects of air temperature on office workers' well-being, workload and productivity-evaluated with subjective ratings. Appl Ergon, 42(1): 29-36. [2] Lan, L., Wargocki, P., Wyon, D.P. and Lian, Z.W. (2011a). Effects of thermal discomfort in an office on perceived air quality, SBS symptoms, physiological responses, and human performance. Indoor Air, 21(5): 376 - 390.

[3] Abbasi, A.M., Motamedzade, M., Aliabadi, M., Golmohammadi, R. and Tapak, L. (2019). The impact of indoor air temperature on the executive functions of human brain and the physiological responses of body. Health Promotion Perspect, 9(1): 55-64.

This article is protected by copyright. All rights reserved 
[4] Krogstad, A.L., Swanbeck G. and Barregård L., Hag-berg, S., Rynell K.B., Ran, A., Andersson, N.H., Calås, B., Håkansson, Y., Jorulf L., Lindberg, G., Persson, Å. and Samuelsson, G. (1991) "A prospective study of indoor climate problems at different temperatures in offices." Gothenburg, Sweden: Volvo Truck Corporation (In Swedish)

[5] Fang, L., Wyon, D.P., Clausen, G. and Fanger, P. O. (2002). Sick Building Syndrome symptoms and performance in a field laboratory study at different levels of temperature and humidity. Proceedings of Indoor Air, 3, 466 - 471.

[6] Seppänen, O., Fisk, W. and Lei, Q.H. (2006) Room Temperature and Productivity in Office Work, eScholarship Repository, Berkeley, California, Lawrence Berkeley National Laboratory, University of California, http://repositories.cdlib.org/lbnl/LBNL-60952.

[7] Lan, L., Wargocki, P. and Lian, Z.W. (2011b). Quantitative measurement of productivity loss due to thermal discomfort. Energy Build, 43: 1057-1062.

[8] Siqueira, J.C.F., da Silva, L. B., Coutinho, A.S. and Rodrigues, R.M. (2017). Analysis of air temperature changes on blood pressure and heart rate and performance of undergraduate students, Work, 57: 43-54.

[9] Geng, Y., Ji, W.J., Lin, B.R. and Zhu Y.X. (2017). The impact of thermal environment on occupant IEQ perception and productivity. Build Environ, 121: 158-167.

[10] Robin, N., Collado, A., Sinnapah, S., Rosnet, E., Hue, O. and Coudevylle GR. (2019). The influence of tropical climate on cognitive task performance and aiming accuracy in young international fencers. J Human Perform Extreme Environ, 15(1): Article 4.

[11] Bao, X.J. and Fan, Q.L. (2018). The impact of temperature on gaming productivity: evidence from online games, Empirical Economics, 1-33. 10.1007/s00181-018-1523-7

[12] Wargocki, P., Porras-Salazar, J. A., Contreras-Espinoza, S. (2019) The relationship between classroom temperature and children's performance in school. Build Environment, vol: 157, pages: 197-204.

[13] Yeganeh, A.J., Reichard, G., McCoy, A.P., Bulbul, T. and Jazizadeh F. (2018). Correlation of ambient air temperature and cognitive performance: A systematic review and meta-analysis. Build Environ, 143: 701-716.

This article is protected by copyright. All rights reserved 
[14] Tham, K.W. (2004) Effects of temperature and outdoor air supply rate on the performance of call center operators in the tropics. Indoor Air, 14 (Suppl 7): 119-125.

[15] Leyten, J. L. and Kurvers, S. R. (2013) Limitations of climate chamber studies into thermal comfort and workers' performance. Indoor Air, 23 (5): 439-440.

[16] Lan, L., Wargocki, P., Wyon, D.P. and Lian, Z.W. (2013). Warmth and performance: reply to the letter from Leyten and Kurvers (2013). Indoor Air, 23 (5): 437-438.

[17] ASHRAE (2017). Standard 55 - 2010: "Thermal Environmental Conditions for Human Occupancy"; ASHRAE. Atlanta USA.

[18] EN16789-1 (2019). Energy performance of buildings - Ventilation for buildings - Part 1: Indoor environmental input parameters for design and assessment of energy performance of buildings addressing indoor air quality, thermal environment, lighting and acoustics - Module M1-6.

[19] Zhang, F., de Dear, R., Hancock, P. (2019) Effects of moderate thermal environments on cognitive performance: A multidisciplinary review, Applied Energy, 236: 760-777.

[20] Hancock, P.A. and Warm, J.S. (1989). A dynamic model of stress and sustained attention. Human Factors, 31(5), 519-537.

[21] Wyon, D. P., Fanger, P. O., Olesen, B. W., and Pederson, C. J. K. (1975). The mental performance of subjects clothed for comfort at two different air temperatures. Ergonomics, 18(4): $359-374$.

[22] Zhang, F., Haddad, S., Nakisa, B., Rastgoo, M.N., Candido, C., Tjondronegoro, D. and de Dear R. (2017a). The effects of higher temperature setpoints during summer on office workers' cognitive load and thermal comfort. Build Environ, 123: 176-188.

[23] Häggblom, H., Hongisto, V., Haapakangas, A. and Koskela, H. (2011) The Effect of Temperature on Work Performance and Thermal Comfort - Laboratory Experiment. In Proceedings of the 12th International Conference on Indoor Air Quality and Climate, Indoor Air, Austin, Texas.

[24] Wyon, D.P., Wyon, I. and Norin, F. (1996) Effects of moderate heat stress on driver vigilance in a moving vehicle. Ergonomics, 39, 61-75

[25] Wyon, D.P. (1996) Indoor environmental effects on productivity. In: IAQ 96 Proceedings

This article is protected by copyright. All rights reserved 
"Paths to better building environments". Baltimore, Maryland: ASHRAE, 5-15

[26] Wargocki, P., Wyon, D.P., Baik, Y.K.,Clausen, G. and Fanger, P.O. (1999) Perceived air quality, sick building syndrome (SBS) symptoms and productivity in an office with two different pollution loads, Indoor Air, 9: 165-179.

[27] ASHRAE (2017) ASHRAE Handbook: Fundamentals, Atlanta, GA, American Society of Heating, Refrigerating and Air-Conditioning Engineers, Inc.

[28] Zhang, X.J., Wargocki, P., Lian, Z.W. and Thyregod, C. (2017) Effects of exposure to carbon dioxide and bioeffluents on perceived air quality, self-assessed acute health symptoms, and cognitive performance, Indoor Air, 27: 47-64.

[29] Åkerstedt, T. and Gillberg, M. (1990) Subjective and objective sleepiness in the active individual, Int J Neurosci, 52: 29-37.

[30] Yoshitak, H. (1973) Occupational Fatigue Approach from Subjective Symptom, Tokyo, Japan, The institute for science of labor (in Japanese).

[31] Hart, S. and Wickens, C.D. (1990) Workload assessment and prediction. In: Booher, H.R. (ed.), MANPRINT: An Emerging Technology. Advanced Concepts for Integrating People, Machines and Organisations. Reinhold, NY, Van Nostrand, 139-183.

[32] Zhou, Q.G. (2000) Deduction of the regressive equation between density and pressure and between density and temperature of saturated vapor, J Chongqing Jianzhu Univ, 22(3): 118-121 [33] Shaffer, F. and Ginsberg, J.P. (2017) An overview of heart rate variability metrics and norms. Front in Public Health, 5: Article 258.

[34] Thayer, J. F. and Lane, R. D. (2000). A model of neurovisceral integration in emotion regulation and dysregulation, J Affective Disord, 61(3): 201-216.

[35] Thayer, J. F. and Lane, R. D. (2009). Claude Bernard and the heart-brain connection: Further elaboration of a model of neurovisceral integration, Neurosci Biobehav Rev, 33(2): 81-88.

[36] Vaikoussis, E., Georgiou, P. and Nomicarios, D. (1994). Tear mucus ferning in patients with Sjögren's syndrome. Documenta Ophthalmologica, 87, 145-151.

[37] Lan, L. and Lian, Z.W. (2010) Application of statistical power analysis-how to determine the right sample size in human health, comfort and productivity research, Build. Environ., 45, 1202-

This article is protected by copyright. All rights reserved 
1213.

[38] Cohen, J. (1988) Statistical Power Analysis for the Behavioural Sciences, 2nd edn, New Jersey, Hillsdale.

[39] Gunnarsen, L. and Fanger, P.O. (1992). Adaptation to indoor air pollution, Energy Build., 18, $43-54$.

[40] Fang, L., Wyon, D.P., Clausen, G. and Fanger, P.O. (2004) Impact of indoor air temperature and humidity in an office on perceived air quality, SBS symptoms and performance, Indoor Air, 14(Suppl. 7),74-81.

[41] Fang, L., Clausen, G. and Fanger, P.O. (1998) Impact of temperature and humidity on the perception of indoor air quality, Indoor Air, 8, 276-284.

[42] Maula, H., Hongisto, V., Östman, L., Haapakangas, A., Koskela, H. and Hyönä, J. (2016). The effect of slightly warm temperature on work performance and comfort in open-plan offices - a laboratory study, Indoor Air, 26: 286-297.

[43] Cedeño Laurent, J.G.C., Williams, A., Oulhote, Y., Zanobetti, A., Allen, J.G. and Spengler, J.D. (2018) Reduced cognitive function during a heat wave among residents of non-air-conditioned buildings: An observational study of young adults in the summer of 2016, PLoS Med, 15 (7): e1002605.

[44] Lee, H., Choi, Y. and Chun, C. (2012) The effect of indoor air temperature on occupants' attention ability based on the electroencephalogram analysis. In: 10th International Conference on Healthy Buildings, 2012, Australia, Brisbane, July $8^{\text {th }}$ to $12^{\text {th }}, 2083-2088$.

[45] General Office of the State Council of the People's Republic of China. 2007. Strict enforcement of construction standards for air-conditioning temperature control (in Chinese). http://www.gov.cn/zhengce/content/2008-03/28/content_4347.htm.

[46] Fan, X.J., Liu, W.W., and Wargocki, P. (2019). Physiological and psychological reactions of sub-tropically acclimatized subjects exposed to different indoor temperatures at a relative humidity of $70 \%$, Indoor Air, 29: 215-230.

[47] van Marken Lichtenbelt, W., Hanssen, M., Pallubinsky, H., Kingma, B. and Schellen, L. (2017) Healthy excursions outside the thermal comfort zone, Build Res Informat, 45 (7): 819-827.

This article is protected by copyright. All rights reserved 
[48] Andersson, J., Berggren, P., Gronkvist, M., Magnusson, S. and Svensson, E. (2002) Oxygen saturation and cognitive performance, Psychopharmacology, 162: 119-128.

[49] Winder, R. and Borrill, J. (1998) Fuels for memory: the role of oxygen and glucose, Psychopharmacology, 136: 349-356.

[50] Benton, D., Parker, P.Y. and Donohoe, R.T. (1996) The supply of glucose to the brain and cognitive functioning, J Biosoc Sci, 28: 463-479.

[51] Clays E., De Bacquer D., Crasset V., Kittel F., de Smet P. and Kornitzer M. et al. (2011) The perception of work stressors is related to reduced parasympathetic activity, Int Arch Occup Environ Health, 84: 185-191.

[52] Endukuru C.K. and Tripathi S. (2016) Evaluation of cardiac responses to stress in healthy individuals- a non invasive evaluation by heart rate variability and stroop test, Int $\mathrm{J}$ Sci Res, 5 : 286-289.

[53] Hammel, J. C., Smitherman, T. A., McGlynn, F.D., Mulfinger, A.M., Lazarte, A.A. and Gothard, K. (2011) Vagal influence during worry and cognitive challenge. Anxiety, Stress, \& Coping, 24 (2): 121-136.

[54] Witterseh, T., Wyon, D. P. and Clausen G. (2004) The effects of moderate heat stress and open-plan office noise distraction on SBS symptoms and on the performance of office work, Indoor Air, 14: 30-40.

[55] Porras-Salazar, J.A., Wyon, D.P., Piderit-Moreno, B., Contreras-Espinoza, S. and Wargocki, P. (2018) Reducing classroom temperature in a tropical climate improved the thermal comfort and the performance of elementary school pupils, Indoor Air, 28: 892-904.

[56] Lan, L., Tsuzuki, K., Liu, Y.F. and Lian, Z.W. (2017) Thermal environment and sleep quality: A review. Energy Build, 149:101-113.

This article is protected by copyright. All rights reserved 